Portland State University

PDXScholar

1978

\title{
Working with Natural Helpers: a Handbook for Social Workers
}

\author{
Lorraine Crawford \\ Portland State University \\ Pamela Smith \\ Portland State University \\ Karen Lynn \\ Portland State University
}

Follow this and additional works at: https://pdxscholar.library.pdx.edu/open_access_etds

Part of the Social Work Commons

Let us know how access to this document benefits you.

\section{Recommended Citation}

Crawford, Lorraine; Smith, Pamela; and Lynn, Karen, "Working with Natural Helpers: a Handbook for Social Workers" (1978). Dissertations and Theses. Paper 2687.

https://doi.org/10.15760/etd.2683

This Thesis is brought to you for free and open access. It has been accepted for inclusion in Dissertations and Theses by an authorized administrator of PDXScholar. Please contact us if we can make this document more accessible: pdxscholar@pdx.edu. 
WORKING WITH NATURAL HELPERS:

A HANDBOOK FOR SOCIAL SERVICE WORKERS

\author{
by \\ Lorraine Crawford \\ Pamela Smith \\ Lynn Taylor:
}

A practicum submitted in partial fulfillment of the requirements for the degree of

MASTER OF SOCIAL WORK

Portland State University

1978 
TABLE OF CONTENTS

Rationale......................... i

Process........................ ii

Limitations and Evaluation.............. vi

The Handbook......................... 1-92

List of Works Consulted................ viii

Appendices........................ xiii 
The practicum consists of a study of methods of identifying and working with natural caregivers, based on previous descriptions in the literature of natural caregivers and their networks, presented in handbook format, and addressed to social service delivery people. Most of the natural helping literature describes natural helpers and natural helping networks. Little is available about the worker helper relationship itself, about how to find natural helpers, and about how to develop and maintain relationships with them. It is this relationship between the worker and the natural helper that we studied and about which we have written.

Included in the sources that we found relating to natural helping are three that do discuss the worker - helper relationship. These gave us a framework with which to begin:

Collins and Pancoast's Natural Helping Networks describes neighborhood helping networks, the concept of the central neighborhood figure, and how these central figures can be supported and strengthened through consultative partnerships with service workers.

Smith's Natural Systems and the Elderly: An Unrecognized Resource describes a one year project in which a Portland neighborhood agency provided services to the elderly, using consultation with natural helpers. 
Patterson's Utilization of Human Resources for Mental Health is an in depth description of characteristics and qualities of natural helpers. Patterson suggests that these same qualities should be the ones to model in developing a consultative relationship between mental health workers and natural helpers.

We originally intended to write a manual presenting a single model for working with natural helpers, a step-by-step process based on the consultation with key helping figures that most of the networking literature described. We designed an interview schedule with social service workers, keeping this model in mind.

We found as we started interviewing, that workers were using many approaches in working with natural helpers. We soon realized that at this time there is no one, ideal model or approach. Since we feel that what is actually happening in practice is very important to the development of such a new way of working, we decided to put together a handbook describing the many ways of working with natural helpers that workers described to us.

\section{PROCESS}

From the beginning we planned to do the practicum collectively. To us working collectively meant each of us being equally involved in. all stages and making decisions by consensus. We chose this method of working because we feel collectively executed products can be superior to individually executed ones, because we all wanted to learn more about writing collectively, and because the process of working together seemed to fit well with our topic. 
Rather than talking with natural caregivers, we chose to talk with agency workers who were working with natural caregivers because we wanted to get information about the worker - helper relationship and because we felt the natural helpers themselves should be interfered with as little as possible: The workers we contacted agreed. They were very protective about the trust they had built with natural helpers. They did not use full names in talking about the natural helpers, and, with one exception, they did not suggest we talk with the natural helpers themselves.

The Literature Review

We spent the first three months of the project reviewing a cross section of the literature representing:

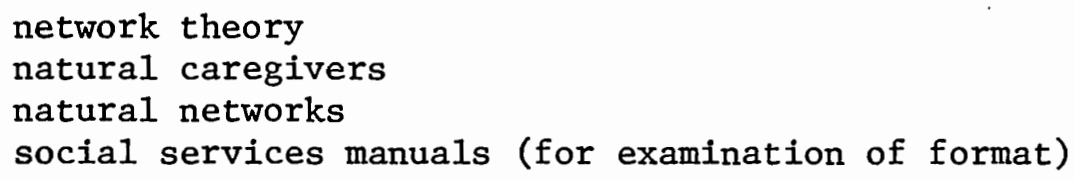

A full bibliography is found at the end of this report, and an annotated list of selected readings is found at the end of the handbook.

The Search for Workers

Although we knew we wanted to interview workers involved with natural caregivers, we didn't have any names or leads. We decided to approach this problem in the same manner that various writers have suggested looking for central figures: 
The Discovery Process

1) Physically define the community.

2) Get to know how it works.

3) Search for informal helping patterns.

4) Contact persons mentioned repeatedly as natural helpers.

We defined the "community" as neighborhood-based service agencies and local people whom we knew had written about working with natural helpers. We contacted central people in our "community" asking if they knew anyone who was working with natural helpers. Soon we had a list of names (see appendix A): Although some names were mentioned repeatedly, we contacted all the names we were given. We followed up on all leads and slowly developed a second list, this a list of people to interview (see appendix B).

\section{The Interviews}

We developed an interview schedule (appendix C) and began our interviews using this schedule. In the midst of the first interview we discovered that the format was not very useful for gathering the kind of information we wanted. Its formality hampered informal discussion. It was designed to focus on one approach, a consultation model with natural helpers. Since people were using many approaches our interview did not get important information. Also, a structured interview did not easily lend itself to free-flowing discussion; neither the form nor our choice of words fit with the subject matter. In fact, people politely smiled and had trouble relating to the professional words we used.

Another discovery we made during the first two interviews was 
that we were interviewing the wrong people. We had started by interviewing directors and supervisors who directed us to agency: outreach. workers. Soon we were revising our list to include these workers and were revising our interview format to one that was much less structured. As we changed from asking planned questions to asking spontaneous ones, the workers began to tell us what they thought was important and how they actually worked with natural helpers. We found the best approach to interviewing was a "chatty" one, sharing information we had learned as well as asking questions.

Initially we planned the search process for two months, but this process continued all the while we did our interviews (four more months). We talked with thirty people during the search and interviewed sixteen workers. (See appendix for lists.) Each worker interview was approximately two hours long. Two of us attended each interview; one of us taped the interview and did most of the talking while the other took notes.

Writing the Handbook

To us, working collectively meant writing collectively. After a two month attempt at sitting down and writing together, we found the best approach was to outline ideas together, write drafts individually, then rewrite the drafts together. Writing together required some of the same commitments as does working with natural helpers; it took time, patience, friendship, working as equals, and compromising our previous writing "styles".

Since working with natural helpers is so new, we found that working 
together afforded us the value of discussion for clearer understanding of new material, more contacts than if we had worked individually, and the support and encouragement of each other.

\section{LIMITATIONS AND EVAULATION}

The information in the handbook is limited by the fact that we only talked with the workers. There is much more information that could be learned from actually going along with them while they do their work. Descriptions of the programs are limited by the way we collected our information. Had we known from the start that we were going to include individual program methods in the handbook we would have designed our way of gathering information differently, spending more time with each program and talking with more workers.

Since what we found in the field did not fit our original intent to present one ideal model for working with natural helpers, we had to change what we did with our information. We tossed out many of our interviews, almost one third of them didn't lend themselves to what we finally put into the handbook. We realized as we began to write that our six months of preparation had given us an overwhelming amount of information about working with natural helpers. Persons doing research in this area in the future may do well to focus on just one aspect of working with natural helpers.

We have mentioned some weaknesses in our information. In spite of these, some very positive results of our process deserve méntion. Both the telephone contacts and interviews with workers sparked much interest in work with natural helpers. People we interviewed were eager to learn how other programs were working with natural helpers. 
As a result, we acted as a vehicle for exchange of information between programs. Many workers requested copies of our final product. We have agreed to send them each a copy of the handbook.

We hope the handbook itself is useful as a way, of sharing information and increasing interest in working with natural helpers. But it is just a beginning. More information is needed about the different ways of working with natural helpers and the impact different methods have on helping systems. 


\section{"IT MAKES GOOD SENSE"}

A HANDBOOK FOR WORKING WITH

NATURAL HELPERS

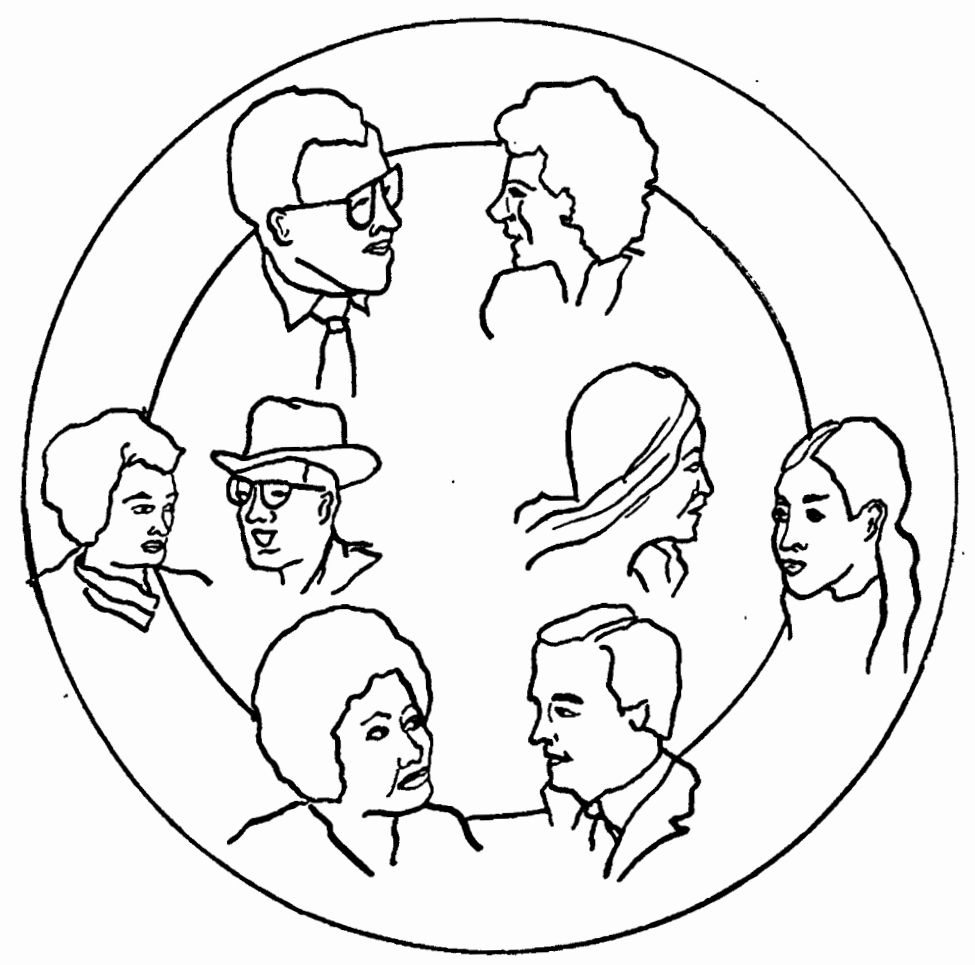


"IT MAKES GOOD SEINSE"

A Handbook for Working with Natural Helpers

\section{Lorraine Crawford Pamela Smith Lynn Taylor}

IIZustrated by: Kathleen Stevenson

(C) 2978 Lorraine Crowford, Pamela Smith, Lynn Taylor 


\section{Contents}

A NOTE FROM THE AUTHORS

ACKNOWLEDGEMENTS

PART ONE: GETTING STARTED

1 Introduction. ............................. 1

2 Natural Helpers............................ 4

Who They Are

What They Do

The Nature of the Relationship

Exercises

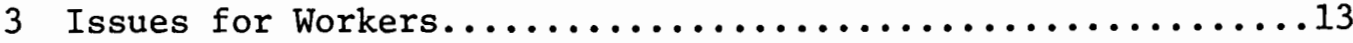

Should You Work With Natural Helpers?

Are You Interfering?

Are You Exploiting?

Should You Train?

Can You Work With Natural Helpers?

Time Barriers

Geographic Barriers

Agency Considerations

Workers' Values

Are You On The Right Track? Evaluating Your Work.

PART TWO: WORKING TOGETHER

Introduction.................................. 30

4 Working With Natural Helpers: Recognizing the Resource......32 Settlement House I

Information and Referral in Senior Centers

5 Working With Natural Helpers: Supporting Their Work......40 A Neighborhood Center

Settlement House II

6 Working With Natural Helpers: Working With Kids.........58

A Youth Service Center

7 Working With Natural Helpers: Improving the Quality

of Life.................................66

A Neighborhood Health Service

An Inner City Project

8 Working With Natural Helpers: Building Networks..........78

A Neighborhood Approach to Childcare

Summary $. \ldots \ldots \ldots \ldots \ldots \ldots \ldots \ldots \ldots \ldots \ldots \ldots \ldots, \ldots, \ldots, \ldots \ldots$

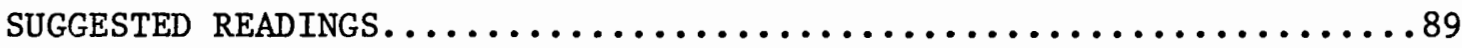




\section{A Note From The Authors}

A11 three of us could remember examples of natural helping in our childhood neighborhoods. All of us had worked with natural helpers at some time or another as agency workers. Then our interest in natural helping developed into our major project while at the Portland State University Graduate School of Social Work.

The suggestion to write a handbook for working with natural helpers was given to us by Grace Boys, who is director of Primary Prevention at the Marion County Mental Health Program, Salem, Oregon. The Primary Prevention Program is currently involved in a demonstration project, acquainting social service workers in Marion County with methods of working with natural helpers. Alice Collins is providing valuable consultation for the project. One of us, Pam Smith, is working directly with the demonstration project at the time of this writing, sharing the information we have learned with the Marion County participants. The handbook is part of that effort.

our efforts in developing the handbook have generated some practical results, Not only have we shared the information we have learned with the Marion County project participants, but we have also shared information among the workers we interviewed. They have been 
very enthusiastic in sharing information with us and about our efforts.

Just a word about our use of quotes and about our choice of wording for the handbook. We intend the handbook to be a further sharing of information among social service workers, especially those interested in beginning to work with natural helpers. We have tried to write in a natural style, avoiding professional words, because it is this natural way of talking the workers use in doing their work with natural helpers. We have made extensive use of their own words through direct quotes. The quotes, which we have boxed for emphasis, are included as an attempt to introduce readers to the unique style of working with natural helpers. It is our hope that through this style of writing readers will be introduced to one of the main themes in natural helping: "be as natural as they are". 


\section{Acknowledgements}

We express our thanks:

to Grace Boys, director of the Primary Prevention Program, Marion County Mental Health, for her enthusiasm and help throughout the entire project.

to All the people we interviewed for their time and interest in our work.

to Sarah Smith and Diane Pancoast for their valuable material and suggestions.

to June Dunn for giving us an office, making it much easier for us to work collectively.

to Kathleen Stevenson, for her wonderful illustrations.

to Donna Battalion, for her many hours typing the handbook. 


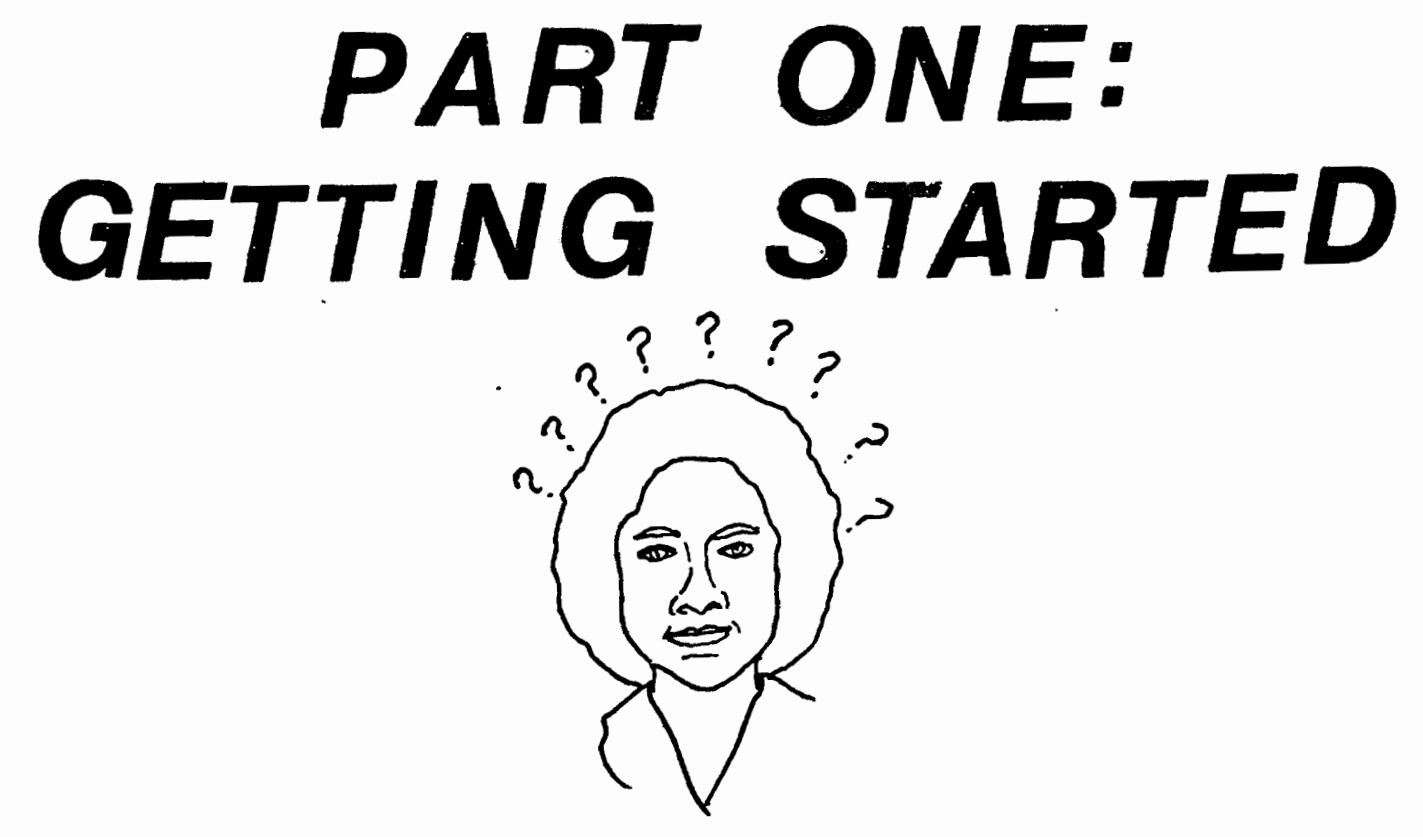




\section{Chapter One Introduction}

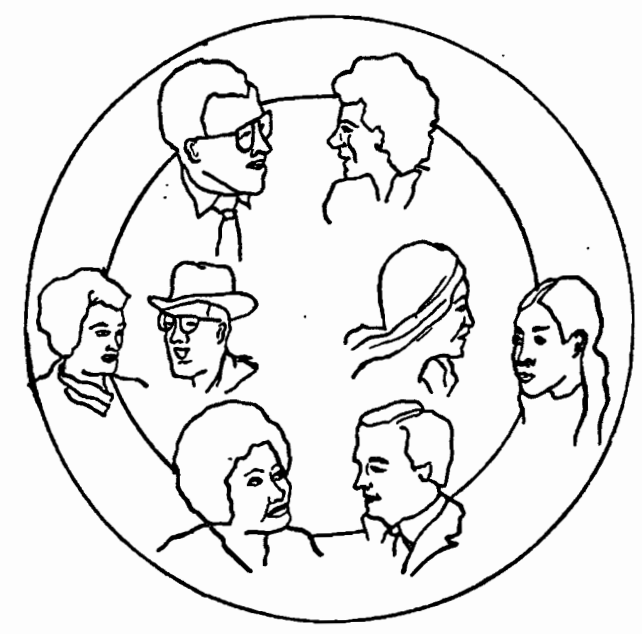

This is a handbook about working with natural helpers, people who spontaneously help others in the course of everyday life. It is specifically written for social service workers interested in this type of work, although the concepts apply to all people in helping professions. We hope it will increase awareness of natural helping, add to the understanding of how natural helpers work, and assist interested workers in beginning to work with natural helpers.

The intent of the handbook is to increase understanding of the ways social service workers can work with natural helpers. To get our information we talked with service workers currently working with natural helpers. Many of the quotes found in the chapters are taken directly from these interviews or from project reports about natural helpers. We felt it was important to use these quotes, because they reflect the unique style of this work.

In working with natural helpers formality is avoided, because it creates an unequal relationship between the worker and the natural helper which prevents them from working together. A casual, informal style is required. The workers we spoke with all deliberately used this sty1e; they felt it was essential. We have chosen to write this 
handbook in the same informal style for similar reasons. We think the quality of informal relationships is best captured in informal terms. We also think it is important for the handbook to be an example of the style of work we are discussing.

Working with natural helpers has to be as natural as what they are doing.

an information and referral worker

Natural helping is not new. People have always helped each other. What is new is that more social service workers are beginning to recognize the value of natural helpers and to search for ways to work with them and to learn from them.

When we work we listen to people...to what they are already doing... Workers don't do this enough.

director of a neighborhood project

\section{To The Reader}

We intend this bookbook to be a guide. We hope you will use it to assist you in thinking about natural helpers and in working with them. While reading it would be helpful for you to relate the infor- 
mation to yourself, your own experiences, your job, and your agency. We found that personalizing the material helped us to understand it. better; the exercises at the end of some of the chapters are included to help you do the same.

This is a personal handbook, describing workers' individual experiences with natural helping. It includes many ways of working with natural helpers from a variety of programs. It also includes common guidelines that all workers felt were essential and shouid be followed.

The handbook is divided into two parts. Part one contains a brief description of natural helpers and a discussion of the issues in working with them, including material to help you think through whether or not you will be able to work with natural helpers. Part Two describes eight programs that work with natural helpers, each in a different way. 


\section{Chapter Two}

\section{Natural Helpers}

When we interviewed social service workers we described natural helpers as untrained, unorganized, voluntary providers of help to friends, neighbors, family or others.

The pharmacist who knows al1 of his customers by name and takes the time to listen.

The teenager who does pregnancy counselling for her friend.

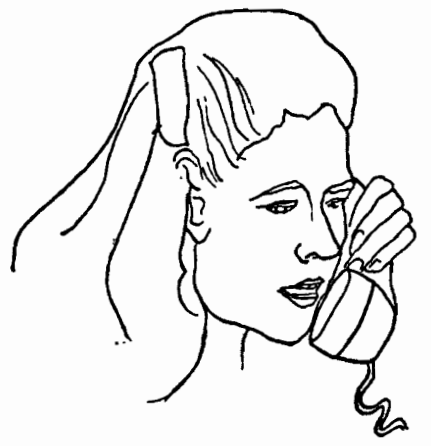

The corner grocer who knows all the gossip and cares about it.

The neighbor who brings hot meals when someone is sick.

All these people were identified as natural helpers. In this chapter we will briefly discuss who natural helpers are, what they 
do, and their relationships to those they help.

\section{Who They Are}

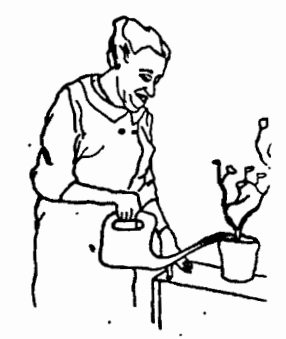

Natural helpers can be anybody - neighbors, friends, family, co-workers, shopkeepers; they can be found in any setting. Even though they can be anybody, anywhere, they have certain things in common. Most are altruistic; they help people out of a deep sense of responsibility.

I believe that one of the most important qualities that these natural helpers share is the feeling of responsibility for others. This seems to be the motivating factor in their behaviors.

Indian social worker

They are good listeners, sensitive to the needs of others.

I'm a listener... On my block, I hear kids talking and talking. I look around and I'm the only one listening.

16 year old gangleader

They are concerned with the problems of individuals rather than larger social issues, and seem to have unlimited amounts of energy to give to others. 
They're healthy... They always have time and energy

for others... They're in charge of themselves...

They're emotionally stable and calm in a crisis.

neighborhood health center nurse

\section{What They Do}

Natural helpers work differently than paid helpers. They're flexible, giving whatever help is needed, whenever it is needed. Because many "work" out of their own homes, they're accessible, available 24 hours a day. They help people they know well and with whom they have something in common. They work without pay, and their services are not organized by other people.

People generally go to paid helpers with problems that require specialized training and to natural helpers with problems that require time and personal labor.

It's incredible what some people do! In order to keep on old woman out of a nursing home, neighbors gave her medications, fed the dogs, cleaned the house, paid her bills, and kept her records straight. 
Natural helpers don't take on a separate role when they help, as paid helpers are trained to do. Rather, they are themselves. They say and do whatever comes to them naturally. They are spontaneous and personally involved, using their own life experiences to help others solve problems.

Some natural helpers help lots of people. Most help only a few. Those who help lots of people are often central figures in a neighborhood helping network. Frequently these are people who have lived in a neighborhood many years, know it's history and are well known by it's residents.

The P. family, represented by three generations, are lifetime residents of the neighborhood... They know what's going on today and most of what's been happening to whom for years past. neighborhood outreach worker

Some specialize in a certain kind of helping because of individual interest.

She's an expert... Everyone in the neighborhood goes to her for advice about their kids. She's raised five kids and always knows what to do.

day care mother

Because natural helpers work out of their own life experiences, where they are in life affects their helping style. Older people 
seem to stress tangible aid and younger people stress a listening ear.

I listen because I think listening is more important than somebody giving a whole lot of advice.

$$
28 \text { year old natural helper }
$$

Most anybody who can keep quiet can listen, but when people have troubles, they want a solution to their problems... That's what I aim for.

67 year old natural helper

They want understanding... Someone who will offer encouragement... and not criticize... Someone who will just be there.

$$
34 \text { year old natural helper }
$$

I think they want action... If you're poor or hurting, sympathy and kind works only go so far.

79 year old natural helper

\section{The Nature Of The Relationship}

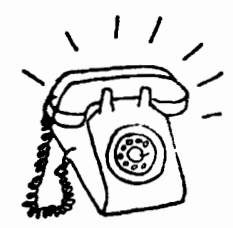

The key to the unique relationship between the natural helper and the person helped is that their roles are interchangeable. Each gives and receives from the other. This mutuality is often based on experiences or problems held in common. 
We're in a poor situation, and I can understand the feelings and situations of other poor people.

rural natural helper

of course, someone can tell you, they can tell you what they think you ought to do. But that isn't like the experience that's shared. It's really the same thing they've shared. You see, that really helps somebody.

rural natural helper

Mutuality requires that people have unlimited access to each other and are attentive to each other's needs. Because people both give and receive they of ten do not define their activity as helping. Rather, it's part of being friends.

The kids won't count the times they help their friends... They only count when someone new comes to them for help.

youth services worker

Although she visits with several elderly women on a regular basis...provides transportation... and help in emergency situations, Mrs. A. does not see these as relationships in which she does anything special. They are long time friends, and each helps the other when the need arises.

neighborhood outreach worker 
The best way to understand who natural helpers are is to look for them in your own life. On the next page are some exercises to help you do this.

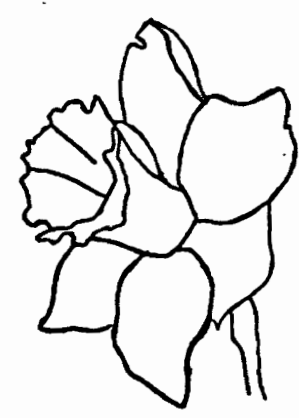




\section{Exercises}

1) Think of your neighborhood when you were a child. Draw a picture of your street. Try to remember names and put them on the houses, stores, etc. Who were the natural helpers in your neighborhood?

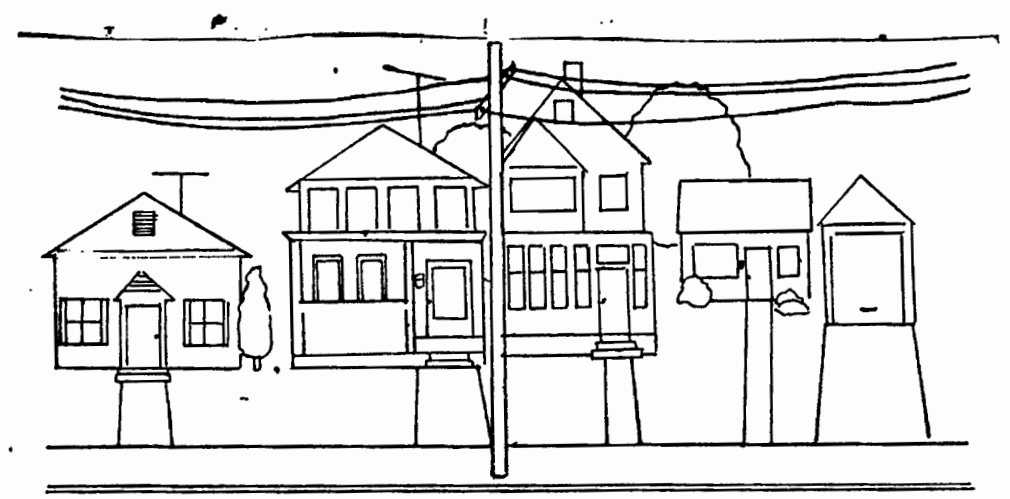

2) Think of your neighborhood now. Who do you go to when you need help? If you're locked out? If you need someone to talk to? If your car won't start? Who do you go to when you need someone to feed your pets or you run out of milk in the middle of baking a cake?

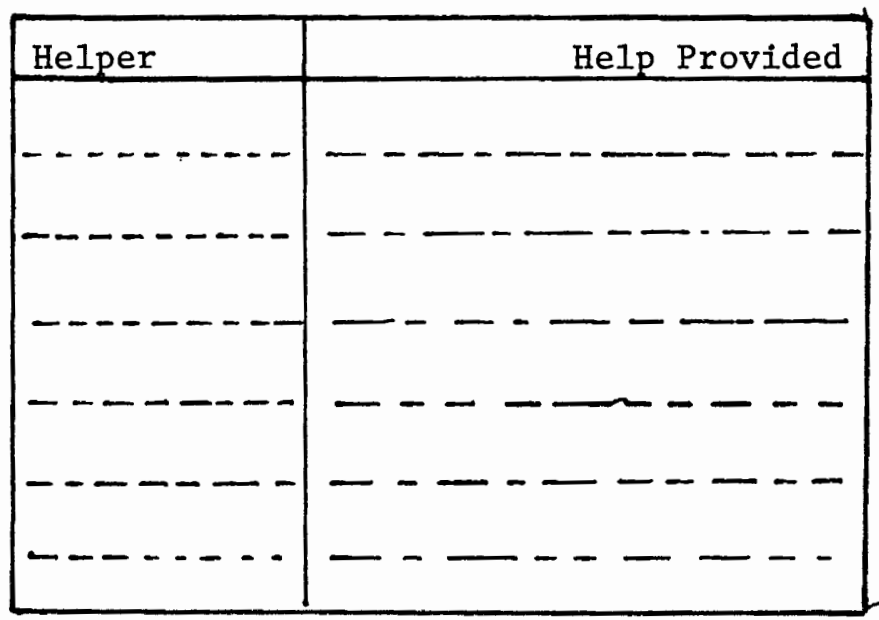


(3) All help doesn't come from neighbors. To get a picture of your own personal helping system, think about all the people who help you. Who do you go to for help? What sort of help? Look at the chart below and fill in the names of the people who help you. Check the ways in which they help. The two empty boxes are for you to fill in types of help that aren't mentioned here.

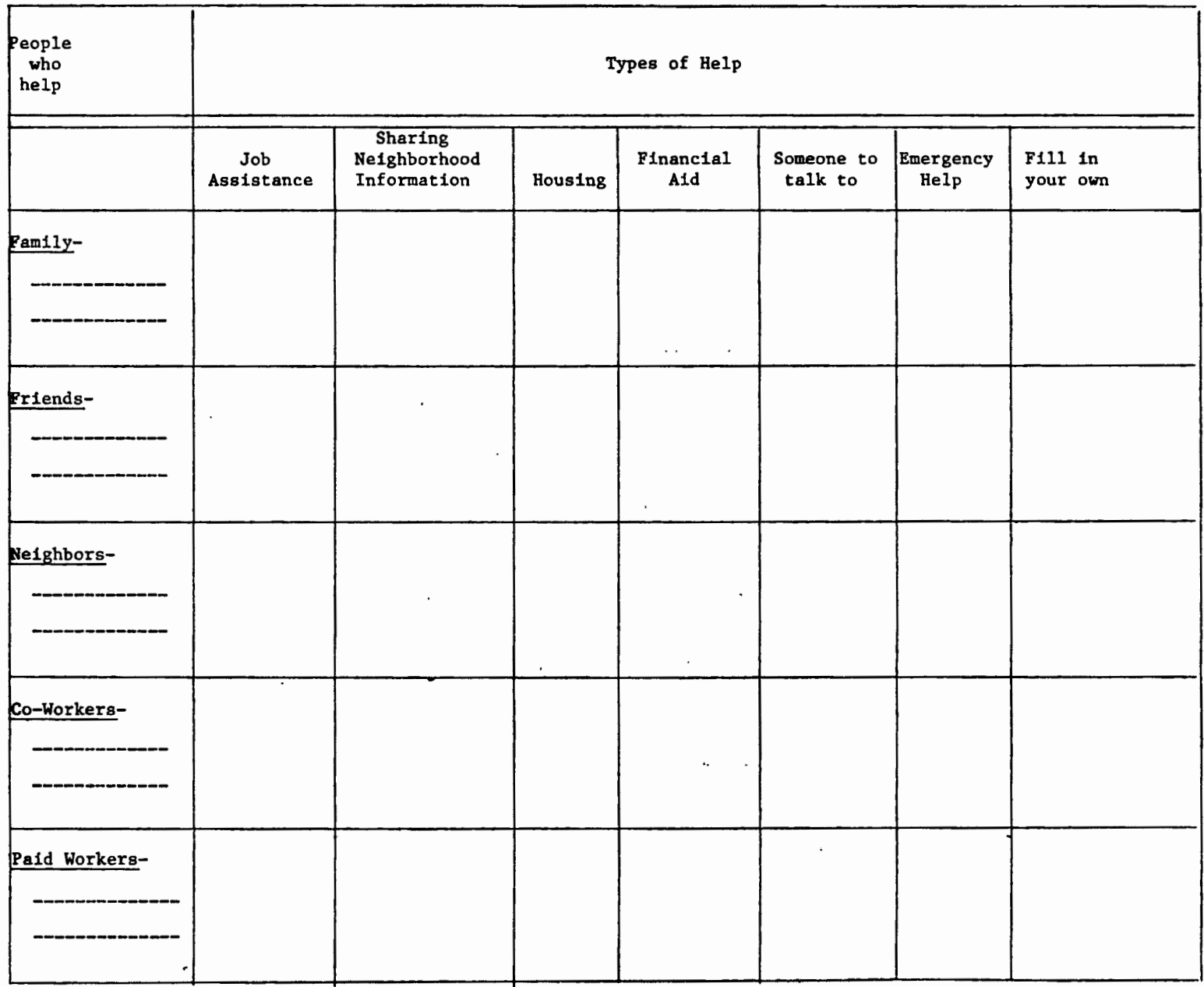

Some people who have studied helping networks have said that people go to neighbors for emergencies, to relatives for long-term help and to friends for support. How true is this statement in your life? Are there some people who help you in more areas than others? How many of these people come to you for help? 


\section{Chapter Three}

\section{Issues For Workers}

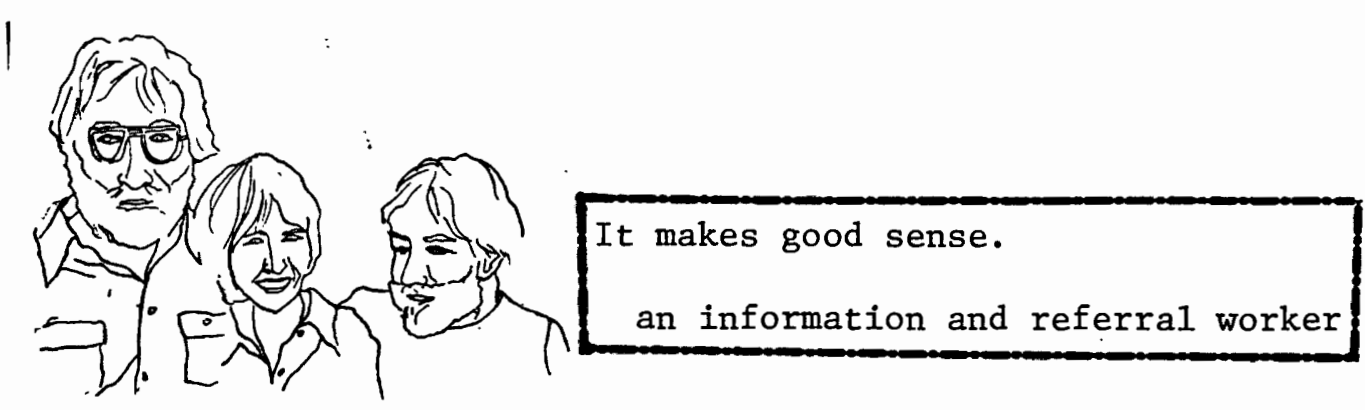

Most people go to friends, neighbors or family with their problems.

People go to friends first...friends know about problems from the start.

youth service worker

Because this is the helping system the majority of people use, it makes sense for agency workers to understand it and learn to work with it. If workers ignore informal helping, they're ignoring most of the daily problem-solving that goes on and missing out on their clients' best resources. 
I believe that the treatment of choice is people solving their own problems in their own way, with as little formal intervention as possible. community mental health worker

Through natural helpers they can learn about the problems and needs of people who can't or won't go to formal agencies -- people they never see.

Working with natural helpers has the advantage of working with an already existing helping system. Services do not disappear when funding does.

If funding runs out, agency workers do too. Natural helpers will be helping long after we're gone.

neighborhood worker

It is an "enabling" process, leaving stronger people in stronger neighborhoods, regardless of whether the agency worker is there or not.

Finally, working with natural helpers can help reduce worker frustration and burn-out. There is a greater need for social services than paid helpers can ever hope to meet. Agencies are overloaded; they're often forced to limit their services to those with the most severe problems. 
Given the extent of the demand for services, as

it occurs within the context of insufficient

staff and funds, our clinics have found it almost

impossible to adequately provide the mandated

range of services.

county mental health department

Working with natural helpers gives workers an indirect way of reaching additional people.

The remainder of this chapter discusses issues that vary for each worker: Should you work with natural helpers, can you work with natural helpers and are you on the right track? Because these are personal questions and every worker will have a different answer, we have addressed them to you -- the individual reader.

\section{Should You Work With Natural Helpers?}

ARE YOU INTERFERING?

The biggest controversy over the work with natural helpers is whether it should be done at all. Natural helping systems may be damaged by professional intervention. If you try to intervene as a social service worker, you may destroy helping patterns that you 
cannot rebuild.

Workers experienced in working with natural helpers stress that paid helpers should attempt to strengthen and support the informal system, not to change it.

Informal, unorganized networks of indigenous helping relationships exist in small towns and rural communities which cannot be duplicated and should not be supplanted by professional practice. rural social worker

How to support without interefering is the real problem faced in working with natural helpers. The basic guideline is:

BE AS NATURAL AS THEY ARE

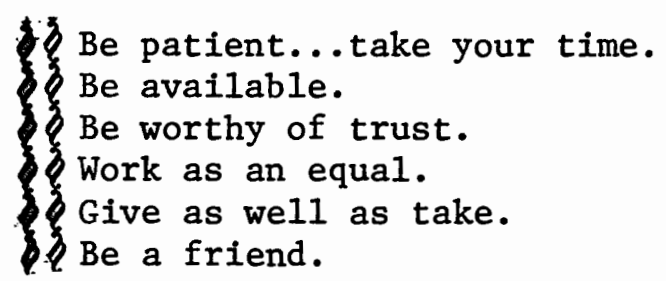

This sounds simple, but is difficult to effect in many agency settings. Part Two of the handbook will give examples of how some programs put these ideas into action.

\section{ARE YOU EXPLOITING?}

Some people see natural helpers as resources that will do their 
work for them. Others have deliberately tried to expand the helping networks of natural caregivers so that more people can be reached. Either approach interferes with the natural system. As a paid helper you cannot expect natural helpers to do your work for you. You are responsible to those in need who prefer or require your trained skills.

Neither should you try to expand natural networks. Natural helpers will help as many people as they are comfortable with. As a result of your support a helper may increase the number she/he helps, but this should not be the aim of the support given. Support should be given to reinforce natural helpers for their work, not to exploit them.

SHOULD YOU TRAIN?

Another common aim of work with natural helpers is to train them to work in a different way - a way that is more in keeping with professional values. Programs with this aim interfere with the natural system. They often make the helper feel less adequate than she/he did before the program began and may result in "referrals" to professionals more often. They also defeat their own purpose. Rather than appreciating the special skills of natural helpers and learning from them, they change what the natural helpers do.

Providing resource information to natural helpers has been viewed by some as training. This has been done by some programs without interfering with the natural helpers' style of work. In fact, natural helpers may request information from paid helpers and this sharing may become part of a reciprocal relationship. 
As a worker beginning a program you should be clear about your own expectations and goals for working with natural helpers. You should think about whether what you want to do may interfere with the natural system, whether you are exploiting it, and what you have to offer to the natural helper.

You have to give something. You can't just take... It may be just leaving enough time to stop and visit once in a while.

information and referral worker

\section{Can You Work With Natural Helpers?}

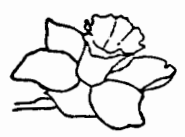

Once you've considered whether you should work with natural helpers, the question becomes, "Can you do it?" To answer this question you need to consider the barriers that you, your agency and other workers impose.

The barriers fall into four main areas:

1) Time barriers.

2) Geographic barriers.

3) Agency constraints.

4) Workers' values.

TIME BARRIERS

Working with natural helpers takes time. It takes time to get 
to know the neighborhood, time to find the natural helpers, and time to develop the relationship.

Once the relationship is established, the time involved is much like that you would take with a friend. You should count on lots of casual activity, like sitting over a cup of coffee in someone's kitchen, chatting about whatever is important to them that day.

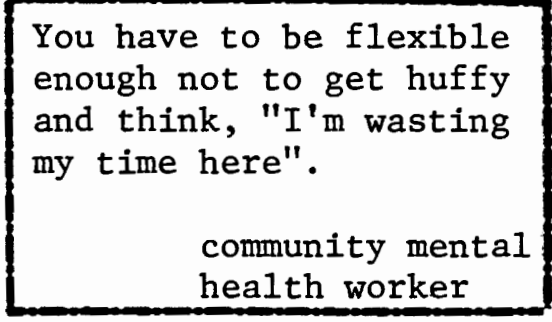

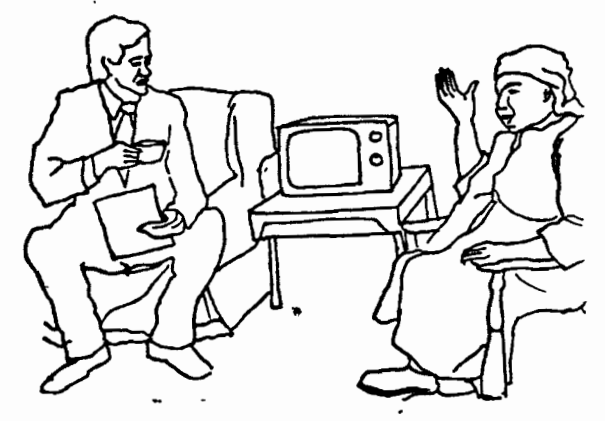

Eventually you will find out about the neighborhood and what the natural helper does.

This all takes more time than the "getting right down to business" style of working in the office. Each visit may take a morning, or even a day, especially if you include the time it takes to get there. If you can't spare this kind of time, it may be impossible for you to work with a natural helper.

\section{GEOGRAPHIC BARRIERS}

Ease in working with natural helpers is also dependent on geographic considerations: the area your agency serves, the location of the agency in the area, and the geographic arrangement of your caseload. 
Natural helpers usually work in one neighborhood. If your agency serves a small area, if $1 t$ is located in a neighborhood, or if your caseload is arranged on a neighborhood basis, it may be easier for you to work with natural helpers. In these situations you may already know and be accepted by the neighborhood and its key helping figures. Your clients may directly benefit from your work with natural helpers, giving you additional justification for what you're doing. Your agency may recognize that strengthening the neighborhood is a legitimate goal and therefore encourage you in this type of work.

If you do find geographic barriers to working with natural helpers (for example, a caseload covering an entire county), the barriers may make the work more difficult but they should not stop you. You can always choose one small neighborhood to concentrate on or identify a natural helper you've come in contact with in your work and begin there. Remember, much of the work already done with natural helpers has been in isolated rural areas where people live miles apart.

\section{AGENCY CONSIDERATIONS}

Another thing you should consider in deciding whether or not you can work with natural helpers is how this kind of work fits with your agency's goals. If your agency is already commited to neighborhood work, you will probably have little trouble getting sanction to work with natural helpers. 
From office-visit oriented agencies, staff responded with surprise and disbelief to the existence of, let alone the extensiveness of informal helping activities in neighborhoods... Staff members of another agency who are directly assigned to the target area instantly recognized both the concepts involved... and were able to provide names of possible natural helpers. community outreach worker

It's also a lot easier to work with natural helpers in agencies that are more responsive to the people they serve than to the requirements of their "巳funding source".

We tell our workers not to push people to get information for forms... The rules are not as important as the people.

director of a neighborhood agency

We provide all services, regardless of funding regulations, to meet the sole goal of keeping people out of institutions.

director of a settlement house program

If funding for your agency is tied to keeping records of how many clients are served and how they are served, you may have difficulty convincing the agency to sanction your work. In working with one helper you may have an indirect effect on twenty people, but you will not be able to document this. If you insist on natural helpers keeping records, it may change their work and interfere with the 
natural system.

WORKERS' VALUES

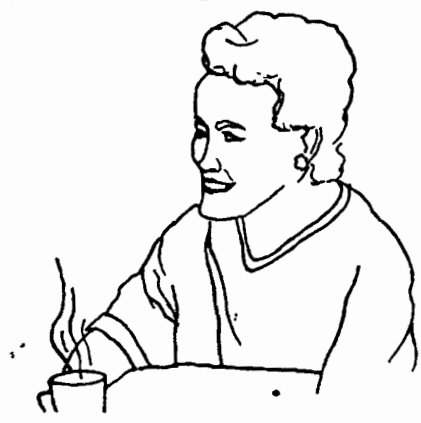

Even if you work for an agency that is perfectly suited to working with natural helpers and you have all the flexibility you need, you still may find a barrier in your own values, You need to look at yourself, your values and your ways of working to see if you can really be comfortable working with natural helpers. Paid workers are trained to separate their personal lives from their working lives. In working with natural helpers you cannot maintain this acquired professional role and be accepted.

There is no professional/personal split in this work. People deal with you as a person.

rural social worker

Even if you're comfortable dropping some of your professional behavior and can be yourself with natural helpers, co-workers with traditional, professional values may have a hard time understanding your personal approach. They may not consider your work as "real work". You're not in the office; you're not working with "identified clients"; you're not delivering a formal service; you're not "working like a professional".

Working with natural helpers seems to come easiest to workers who already assume that people can and do help each other successfully. They have often experienced this type of help and recognize 
its worth. Because these workers already value the work of natural helpers, they are able to work with them as equals.

$$
\begin{aligned}
& \text { It's been part of my lifestyle all along. I } \\
& \text { learned it from my father... He is a natural } \\
& \text { caregiver - a person who people call all night } \\
& \text { long... For me it just seems that everybody does } \\
& \text { have potential and people do help each other, } \\
& \text { so why not give credit to the people of the } \\
& \text { Watertown community? } \\
& \text { community service worker }
\end{aligned}
$$

Working with natural helpers is a new way of working for many. Initially any new way of working creates problems because it forces you to re-examine your assumptions and goals.

This project forced us to look at ourselves... It brought about many long painful sessions among team members about where we should and should not be putting our energies... Changing the work patterns and ways people generally consider themselves working is a major undertaking. Altering the methods of delivering services is a monumental task.

rural mental health worker

You really need to look at your own values to see if they will

allow you to comfortably work with natural helpers. The work should feel natural to you. Remember the guideline: "Be as natural as they are". 


\section{Are You On The Right Track? Evaluating Your Work}

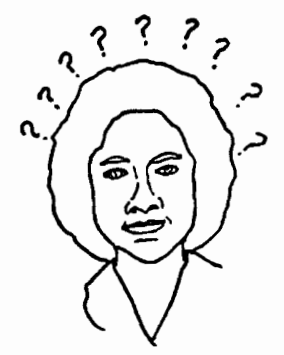

Once you've started to work with natural helpers, evaluation of your work becomes an issue. Old ways of determining whether you're doing a good job probably will not apply because you won't see the direct results of all your efforts. The credit will rightfully go to the natural helper and not to you.

I just pass on suggestions.... It's their work and they do it.

community worker

The workers we interviewed who are working with natural helpers have developed new ways to see if they're on the right track. Some workers keep track of the number of times natural helpers ask for advice. They see this as an indication that a relationship is developing and they are seen as helpful by the helper.

A major criteria for evaluating... was the number of callbacks made to the staff by helpers. 
I know I'm doing a good job when they smile and ask me to come back.

community worker

Others look for evidence that natural caregivers are beginning to see them as helpers in all areas, not just those involving agency work. The workers see this as an indication of being accepted as friendly equals or "good neighbors" by the helpers.

It's hard for me to stop working... I go to the grocery store and people ask me who can mow their grass... They ask me about everything else other than childcare!

community day care worker

People begin to see us as resource people for everything, not just health needs. One natural helper called to find out where to buy garbage bags.

community health worker

These measures of how well you do your work have more to do with the process of developing and maintaining relationships with natural helpers than reaching long-term program objectives, such as strengthening helping networks.

In most cases the workers we interviewed assumed that working through natural systems was a better way to work. They were primarily 
concerned with evaluating their own ways of working with natural helpers, not with measuring the impact of their work. Until there is better understanding of how to work with natural helpers, workers examining their own process is probably the most useful type of evaluation since it may keep them from seriously damaging natural systems.

This is a new field for many workers. There is little written about it. Many of the "do's and don'ts" are different from traditional, professional ways of working. For these reasons, it is very important to carefully consider how you plan to work with natural helpers, what results you are looking for and how you will overcome the barriers that may exist. We hope this chapter has made you aware of some of the issues that need to be considered. The exercises that follow are designed to help you relate the issues to your specific situation. 


\section{Exercises}

(1) The chart below describes the minimum requirements for working with natural helpers. (It is, of course, desirable to have more than the minimum.) The ways of working with natural helpers are listed in order of how much time they require from the worker and/or the agency. The last column lists the programs described in the handbook that use this method.

To find where you/your agency is on the chart, use your location, the number of staff available for working with natural helpers, and the amount of time you have to spend. You can then determine from the chart:

a. which ways of working are possible for you/your agency.

b. which programs described in the handbook worked in these ways.

\begin{tabular}{|c|c|c|c|c|}
\hline & WAYS OF WORKING & AGENCY LOCATION & STAFE INVOLVEAENT & $\begin{array}{l}\text { PROGRAM EXAMPLES } \\
\text { IN HANDBOOK }\end{array}$ \\
\hline & $\begin{array}{l}\text { Be aware of natural } \\
\text { helpers in your clients } \\
\text { lives and nelghborhoods }\end{array}$ & Anywhere & 1 or more workers & $\begin{array}{l}\text { Settlement I } \\
\text { Central I \& } R\end{array}$ \\
\hline & $\begin{array}{l}\text { Outreach to natural } \\
\text { helpers, encouraging } \\
\text { referrals. }\end{array}$ & Anywhere & 1 or more workers & Settlement I \\
\hline 点 & $\begin{array}{l}\text { Utillze natural } \\
\text { helpers to plan agency } \\
\text { goals and objectives. }\end{array}$ & Anywhere & $\begin{array}{l}\text { administration } \\
\text { and workers }\end{array}$ & $\begin{array}{l}\text { Health Service } \\
\text { Inner City Project } \\
\text { Childcare Project }\end{array}$ \\
\hline 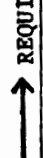 & $\begin{array}{l}\text { Exchange resource } \\
\text { Information with } \\
\text { natural helpers. }\end{array}$ & Anywhere & 1 or more workers & $\begin{array}{l}\text { Central I \& R } \\
\text { Settlement II } \\
\text { Health Service } \\
\text { Youth Project }\end{array}$ \\
\hline & $\begin{array}{l}\text { Support natural } \\
\text { helpers in their } \\
\text { work. }\end{array}$ & Anywhere & 1 or more workers & $\begin{array}{l}\text { Senior Center } \\
\text { Settlement II } \\
\text { Health Servtre } \\
\text { Youth Projeat }\end{array}$ \\
\hline & $\begin{array}{l}\text { Design programs to } \\
\text { include natural } \\
\text { helpers. }\end{array}$ & Anywhere & $\begin{array}{l}\text { administration } \\
\text { and workers }\end{array}$ & $\begin{array}{l}\text { Senior Center } \\
\text { Settlement II } \\
\text { Health Service } \\
\text { Inner City Project } \\
\text { Youth Project }\end{array}$ \\
\hline 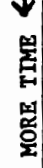 & $\begin{array}{l}\text { Model natural } \\
\text { helpers' style in } \\
\text { agency work. }\end{array}$ & Nelghborhood & $\begin{array}{l}\text { administration } \\
\text { and workers }\end{array}$ & $\begin{array}{l}\text { Senior Center } \\
\text { Childcare Project } \\
\text { Health Service } \\
\text { Inner City Project }\end{array}$ \\
\hline 总 & $\begin{array}{l}\text { Become part of } \\
\text { the helping } \\
\text { network. }\end{array}$ & Neighborhood & $\begin{array}{l}\text { adninistration } \\
\text { and workers }\end{array}$ & $\begin{array}{l}\text { Bealth Service } \\
\text { Childcare Project } \\
\text { Inner City Project }\end{array}$ \\
\hline
\end{tabular}


(2) The chart in exercise one includes ways that both workers and administrators work with natural helpers. This exercise looks only at the four ways that workers work with natural helpers. A list of specific tasks follow each way of working. As you read along, answer the questions, circling yes or no. Use your answers to see in which ways you're able to work at this time.

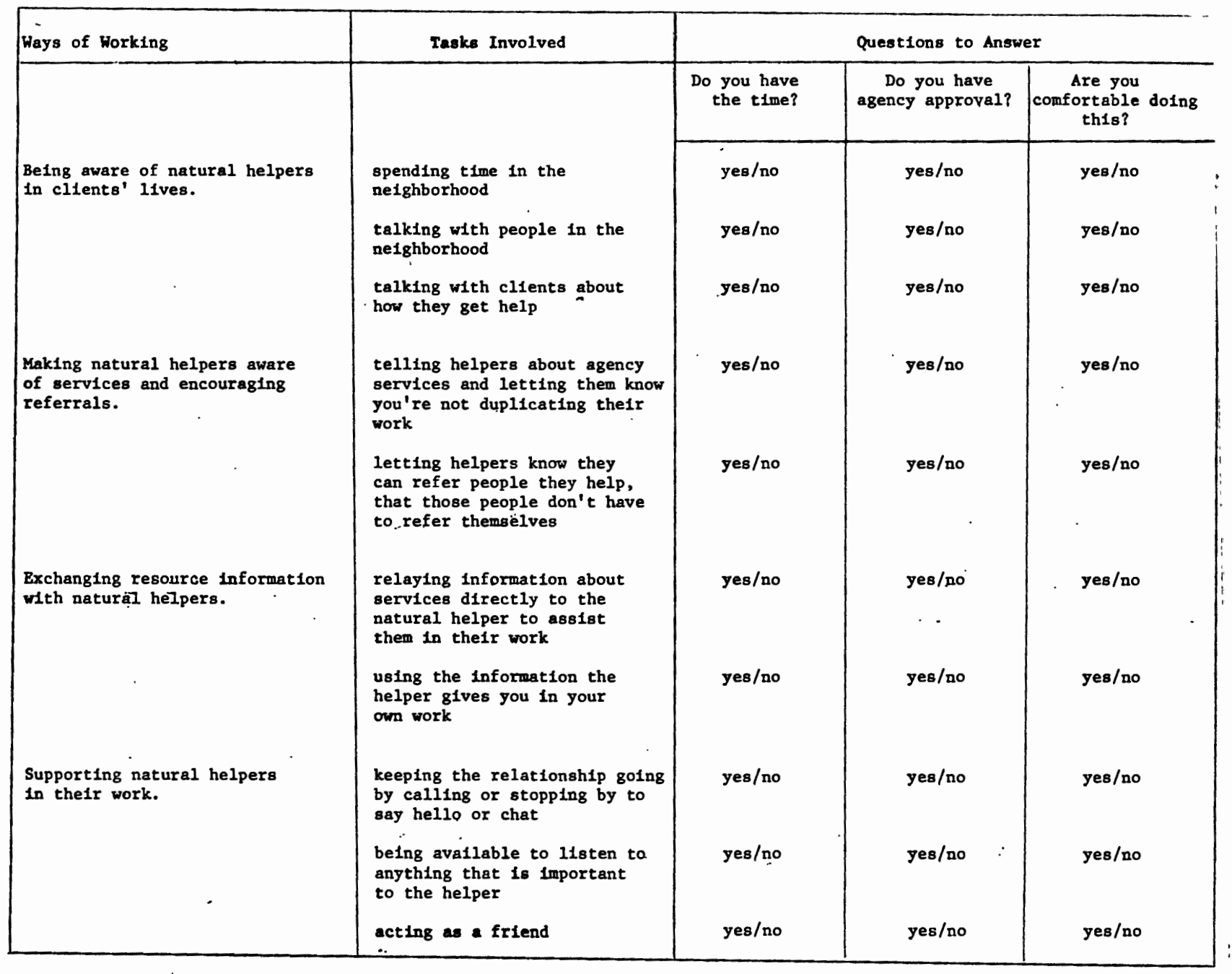




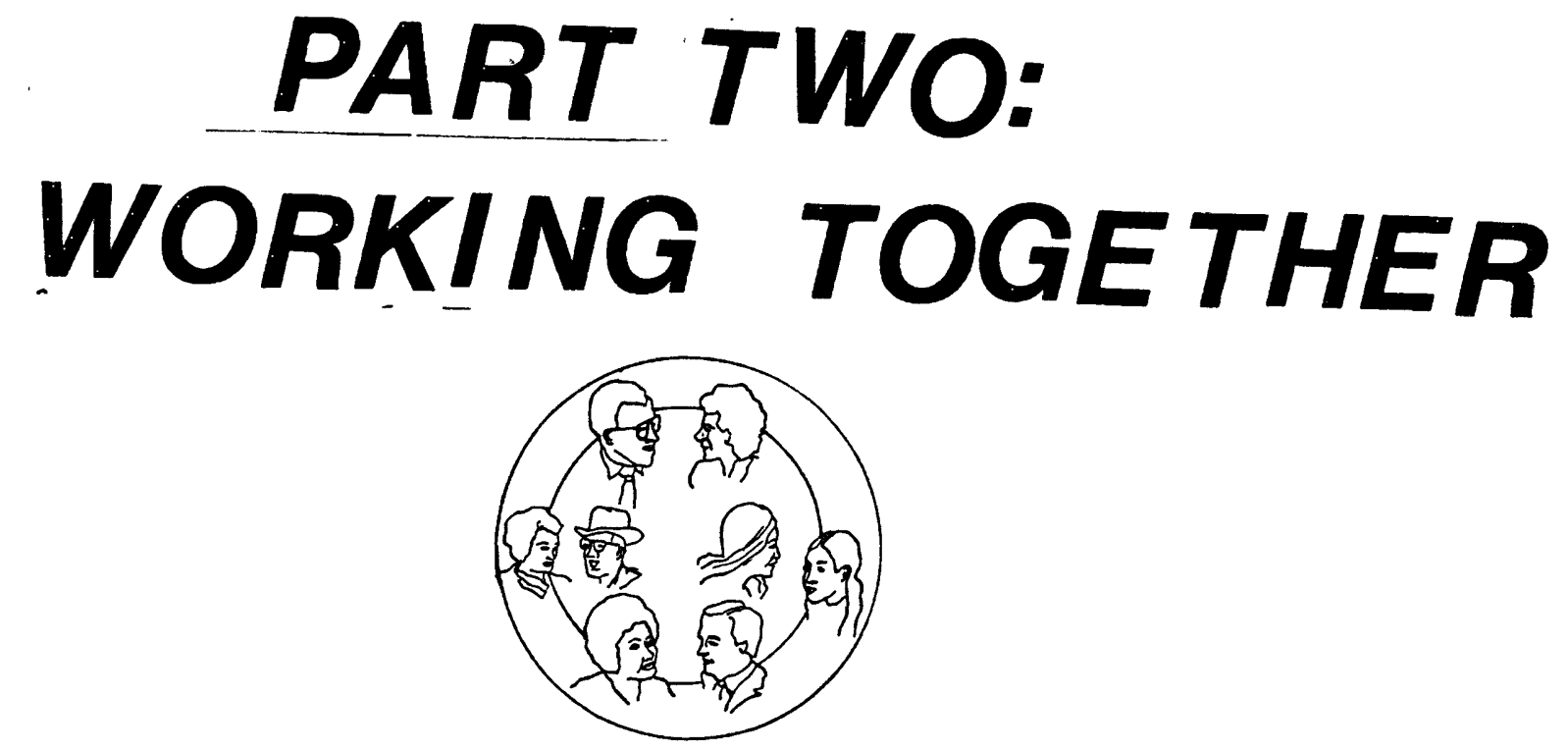




\section{Introduction}

Part Two contains five chapters, each describing programs that work with natural helpers. We have grouped programs that we thought used a similar approach into a single chapter, but within the chapters each program is treated separately. Whenever possible we divided the material from each program into three sections: DESCRIPTION, WORKING WITH NATURAL HELPERS, and EVALUATION.

Some of the programs work with natural helpers who are similar to those described in Chapter Two. Others work with people (such as daycare providers, storekeepers, bartenders, hotel owners, and beauticians) who help as an extention of their official jobs. We have included the second type of program because these "official" helpers are often the most visible ones and can be the starting point for many workers who want to work with natural helpers.

The programs are also in varying stages of development. Those in Chapter Four have just begun, taking the first steps to make workers aware of natural helpers; the others are fully developed around the concept of natural helping and have been working with helpers for a number of years. This variety allows the reader to examine the particular programatic problems and concerns that arise at these stages of 
development.

The programs included in Chapters Five and Six work with natural helpers similar to those described in Chapter Two. In contrast, the programs in Chapter Seven work with a wider variety of helpers, while the program in Chapter Eight focuses on helping networks rather than individual helpers. 


\section{Chapter Four}

\section{Working With Natural}

\section{Helpers: Rocognizing The Resource}

The two programs described in Chapter Four are both small programs that are in the beginning stages of working with natural helpers. One is an information and referral agency $(I \& R)$, the other a settlement house. Each program recognizes the importance of existing natural caregivers and has taken initial steps to incorporate the caregivers into their work.

The $I \& R$ agency has begun by training workers to be aware of natural helpers and to see them as unique sources of information. This was the only agency we found that is introducing the concept of natural caregivers into their training for workers. So of ten the reverse is true; it's the natural helper who is being trained!

The settlement house has begun to work with natural helpers who have voluntarily provided them with information about people they're helping. Staff members visit shops, groceries, taverns, and launderies in the neighborhood to let proprietors know about their services. Often these people are helpers and will "spread the word". The program responds to requests for assistance both from the proprietors and from other helping neighbors in the community.

The settlement house feels that providing a place for community 
residents to meet each other is the best way it can promote natural helping relationships. It is currently involved in expanding its facilities so that there will be more opportunity for this to happen.

\section{Settlement House I}

DESCRIPTION

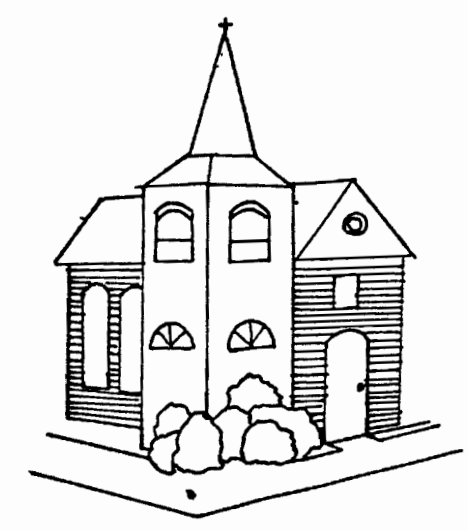

Settlement House I proiides services to all age groups, from pre-schoolers to the elderly. It's primary goal is to provide a mechanism for neighborhood cohesiveness. The senior center program of the settlement house was identified as the one working with natural helpers, so we interviewed three workers from this program.

The workers are involved in providing services directly to seniors through going out to their homes. They provide homemaking, transportation, and counselling services, as well as coordinating food and health services provided by other agencies. They also provide education programs for seniors through local churches and community centers. 
WORKING WITH NATURAL HELPERS

The staff members at this agency see the neighborhood as unique becanse of the predominance of apartment living. People live close together, and they cherish their privacy. The settlement house workers respect this need for privacy; their work is guided by it.

I'd never consider going door to door to find out about the neighborhood. I'd rather visit on a park bench.

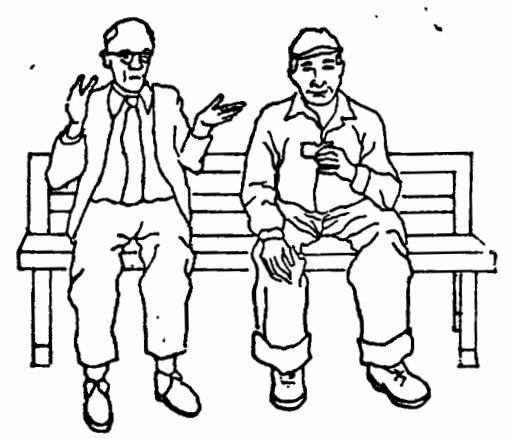

Because of their respect for this need, they do not "search" for natural helpers. Rather, they make themselves visible and wait for natural helpers to call them.

There are several kinds of natural helpers who contact the settlement house to give them information about neighborhood residents, to ask for services for people that they are helping, or to simply inquire about people they haven't seen for a while.

Since the elderly residents of the neighborhood have limited mobility, they become regular customers of particular shops and taverns. When one of their "regulars" doesn't come in for a while, a shopkeeper or bartender will call the settlement house. 
Sometimes a shopkeeper calls us and asks about

a customer that hasn't been around in a while.

They want to know if we've had any contact

with them; usually they're concerned about their health.

A worker will follow this kind of call with a home visit to make sure everything is $0 . \mathrm{K}$.

Other natural helpers that call the settlement house are the

"apartment monitors". These people are residents of apartment buildings

who are elected by other residents to check on people who have known

health problems and to get help when it's needed. Often they'11 cal1

the settlement house when they see a need for service.

The settlement house workers take the time to talk informally

with these natural helpers on the phone or in person whenever a contact

is made. They see this as a valuable first step toward building a

relationship with them, and see it as supporting existing helping

efforts.

PROBLEMS

Since the neighborhood has a high percentage of retired seniors living in high-rise apartments, there are particular problems in both giving and discovering natural care. The settlement workers described two of these problems: 
1) Apartment living seems to foster guarding of privacy. People live in very close quarters and are reluctant to open their doors.

People don't want to open their doors for the whole world to see their lives...they tend to keep to themselves and keep their problems to themselves and tend to mind their own business.

2) Many of the elderly people who live in apartments are in failing health, with low energy and sometimes disabled. Often they have moved into an apartment because they can barely take care of themselves; they have very little "extra" to help other people.

\section{EVAULATION}

The settlement house is aware of these problems. As a result of gaps in their current program, they have decided to create a place for seniors to come together to meet each other as well as to meet younger people. They feel casuád social gatherings are the best way to facilitate formation of natural helping relationships without threatening the privacy carefully guarded by neighborhood residents. 


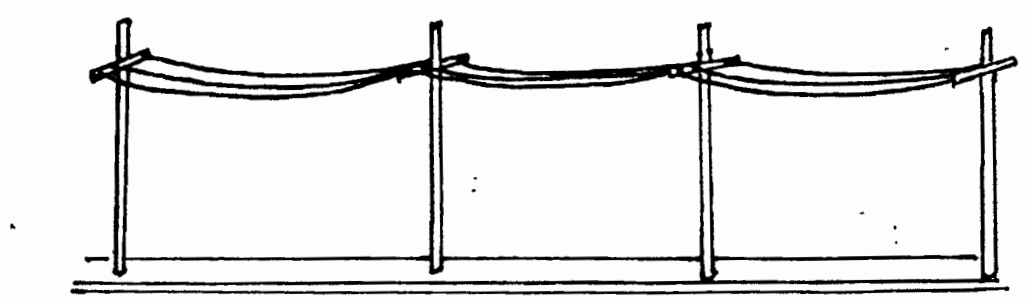

\title{
Information And Referral In Senior Centers
}

\author{
DESCRIPTION
}

We interviewed the program coordinator of a central information and referral ( $I \& R$ ) service that provides $I \& R$, advocacy and followup services in four counties. She is working toward coordinating a network of $I \& R$ workers in local senior centers throughout the counties. Part of her job is to provide training for these workers.

WORKING WITH NATURAL HELPERS

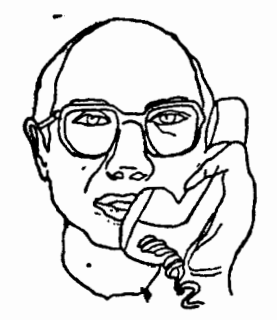

The coordinator is not currently training $I \& R$ workers to work with natural helpers although she would like to do this when she has more time. She is talking to workers informally, trying to help them to be more aware of "good neighbors" and to keep track of them.

It's important to make the $I \& R$ workers aware that good neighbors are there and that they are important.

To convince the $I \& R$ workers of the importance of working with 
good neighbors, she uses what she calls an "it makes good sense" approach. She points out that good neighbors know the local information about what's going on in a neighborhood and can be used as information resources. She does not think that good neighbors should be used to provide additional services.

Natural helpers do not need more work. If I needed a specific service, like a ride for someone, I'd call on a volunteer, not a natural helper.

In her talks with $I \& R$ workers, she asks them to keep in mind that the relationship should be reciprocal, that they have to have something to give to the natural helper in return for the information they receive. She suggests that workers may provide support to natural helpers by being good listeners and by acknowledging the help that

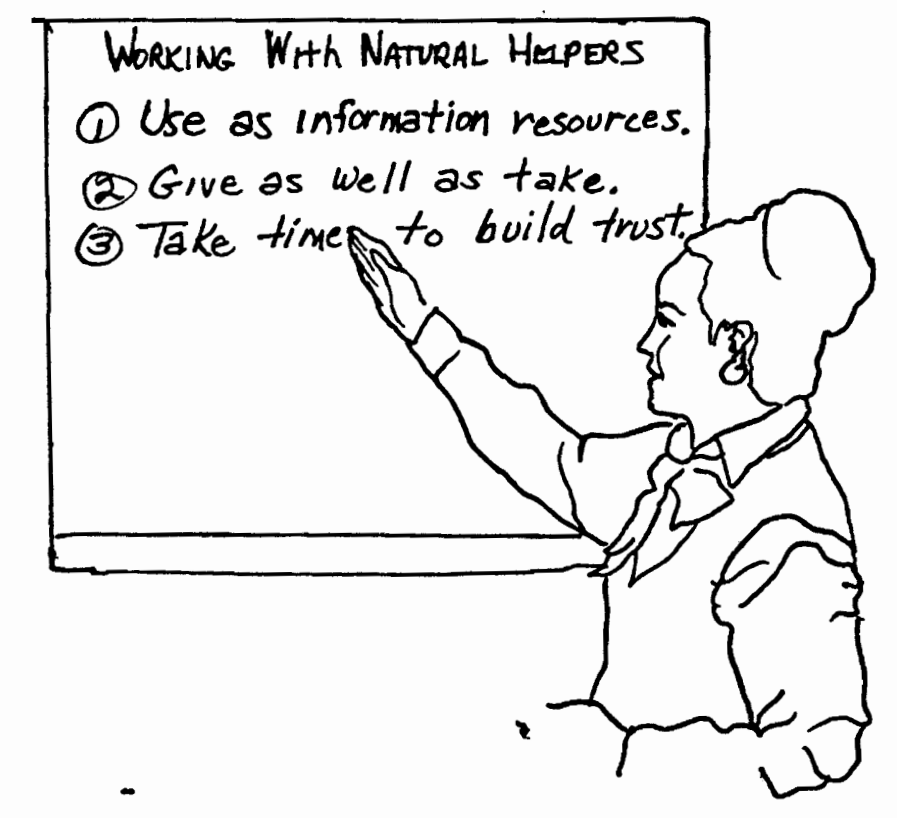


helpers provide. They also may be able to add to the helpers repetoire of resources by passing on new information. In both cases, the workers must plan enough time in their schedules to get to know the helper, to talk casually on the phone or drop in for a visit, to share, to build trust.

Informally encouraging I \& $\mathrm{R}$ workers to be aware of good neighbors is all the coordinator is doing right now. She thinks it is possible to train these workers to work with natural helpers, to find key contact people, to develop files and use them to support and strengthen helping networks. However, when talking about these possibilities, she stressed that training $I \& R$ workers alone will not make significant changes in an agency. Their work will make sense only if other workers in the agency also are recognizing and working with natura1 helpers.

I'd like to think that we're developing a way of thinking about service delivery. 


\section{Chapter Five}

\section{Working With Natural Helpers: supporting their work}

The two programs included in Chapter Five use a similar procedure for finding natural helpers and have based much of their work on Sarah Smith's Natural Systems and the Elderly: An Unrecognized Resource. They both work with the elderly and put much time and energy into working with people identified as natural helpers among the elderly. Both stress being "good neighbors" themselves, taking the time to get to know the neighborhoods and areas their programs serve. Perhaps the most striking characteristic of the two programs is their recognition of natural helpers as a mainstay source of helping among the elderly, and their commitment to supporting this existing way of helping.

Although the two programs operate from the same basic philosophy (that natural helpers exist, that they do an indispensible job, and that agencies should not tamper with them or try to change them), they differ in what they stress as important in the ways they work with natural helpers. The neighborhood service center stresses "going the extra mile" in an approach that focuses on treating people as unique individuals. The settlement house defines the most important part of its work as "getting to know the neighborhood", in 
an attempt to be part of it. In this way it can act as backup for services natural helpers are unable to provide or can no longer provide due to illness or death or "burn-out". 


\title{
A Neighborhood Center
}

\author{
DESCRIPTION
}

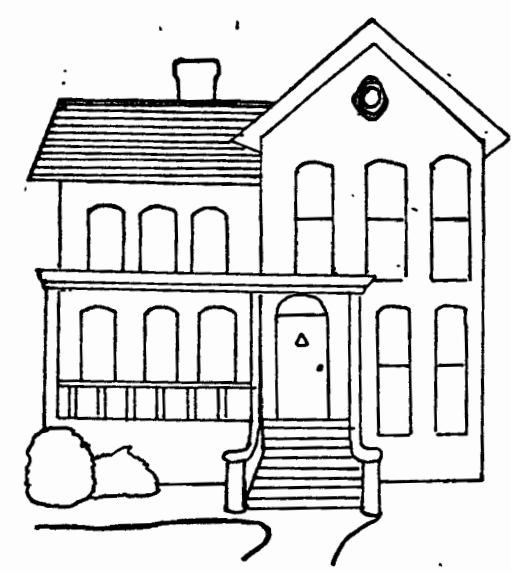

We interviewed a field worker of a small, neighborhood center for the elderly. The center is housed in an old home in a residential area of the city. The idea for this center came from two women who had previously worked at a traditional senior center and had become frustrated with what they saw as a lack of options available for many people. They decided to create a center which would be an alternative to this and would provide the options they felt had been missing.

The biggest difference between this center and the more traditional senior centers is its informal, neighborly focus. It is in a house, visible to and a part of the neighborhood. It has created a casual, homelike atmosphere where people can socialize and spend their time in whatever way they choose without being over-organized. There are classes, scheduled outings, activities, services, and plenty of free time and space for doing whatever they like. 
NEIGHBORHOOD OUTREACH :

Within the center, the program that does the most work with natural helpers is the outreach project. In designing this project, the staff deliberately chose to work with natural helpers because their funding from the federal government was time limited and no one was sure that the city, which funds the rest of the programs, would pick it up.

We wanted something that would last in the neighborhood even if the center's involvement was gone.

The staff of the center basically adopted the outreach program outlined in Sarah Smith's Natural Systems and the

Elderly - An Unrecognized

Resource to begin their work with natural helpers. They even had a poster made from NATURAL NETWORKS AN UURECOGNIZED RESOURCE 和工坎

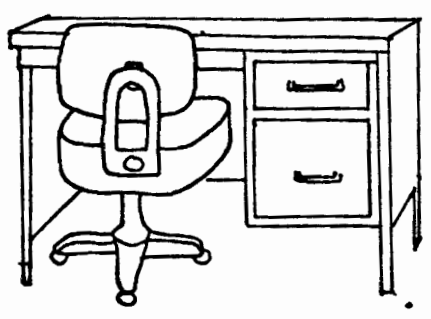

the title. 
Their process was as follows:

1) They used natural boundaries (busy streets, railroad tracks, etc.) to define their area.

2) They developed a map of the area to be covered ( 170 square blocks), divided it into six sections, and colored each block as it was canvassed.

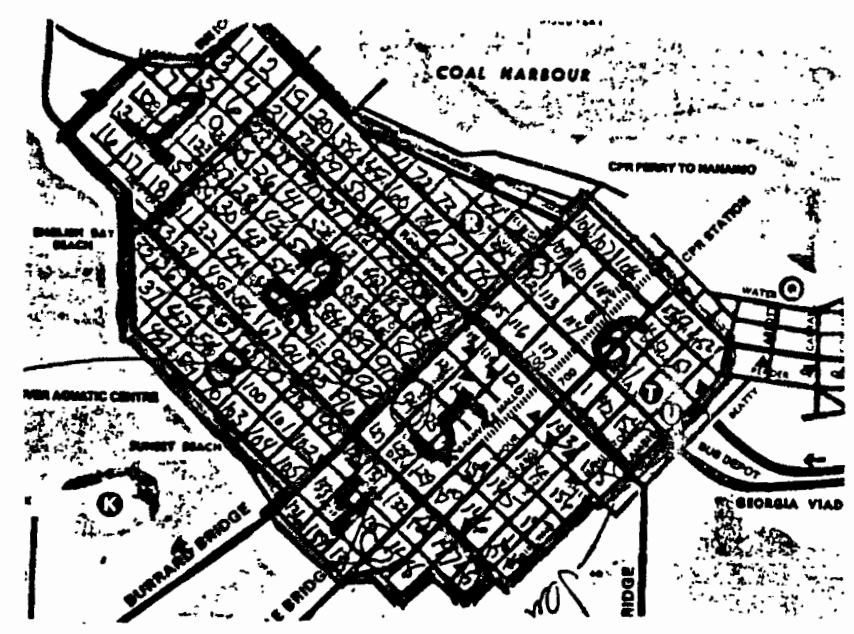

3) They canvassed the neighborhood to locate elderly who didn't use the center.

4) They kept "Block Cards" for each block, listing each address, and whether or not an elderly person lived there.

5) They talked with all the elderly people in the 170 square blocks about the center and it's programs.

\section{BLOCK CARD}

Block $\# 105$

3203 -SE PInE

3205 _SE PINe

3207 SE Pine

3209 SE PIne

3211 SE Pine elderly elderly elderly 
6) They enlisted 67 Block Workers, people who lived on a block and were willing to be responsible for picking up monthly calendars at the center and delivering them to the elderly on their block who wanted them.

7) They asked these Block Workers to stop and chat with each elderly person every month. The center sees them as their direct link with the 1200 elderly in the community who receive calendars.

\section{Center $\longleftrightarrow$ Block Worker $\longleftrightarrow$ Elderly}

8) They keep cards on each Block Worker listing who she/he delivers calendars to.

BLCCK WORKER CARD

Block Worker: Amy Schroeder

484 . Braille 333 Columbus

486. Braille 335. Columbus

488 Braille 337.Columbus

490_Braille 339 Columbus

The card systems that record this information are crossindexed, very detailed, and easy to use. The staff has consciously chosen to use cards and visual aids as a means of keeping track of their work. 
Visual aides give you an idea of where you are and what you can do... They keep you in reality.

FINDING THE NATURAL HELPERS

To find natural helpers the workers canvassed the total area a second time, talking to everyone, young and old alike. The steps they followed were:

1) Block by block they talked to everyone who would talk to them, asking, "What's going on?"... "Who do you know?". They found that generally people knew at least the neighbors next door and across the street.

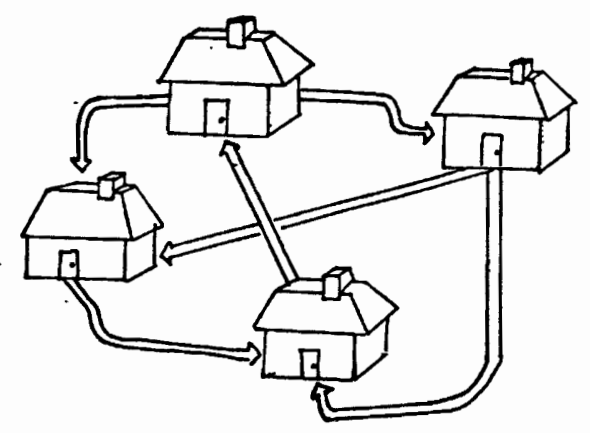

2) They asked about the ways individuals helped each other. "With whom do you exchange help?" 
3) They keep Helping Cards on every house.

HELPING CARD

Block $\# 103$

Name

Address

Senice provided

To.

First Contact

Follow up visits

4) If people are interested in doing more for others, they list them on a Service Card and volunteer to provide introductions to people who want the service.

Often the two people knew each other previously but were not now in contact. "... Oh yes, Mrs. S., I used to see her at..."

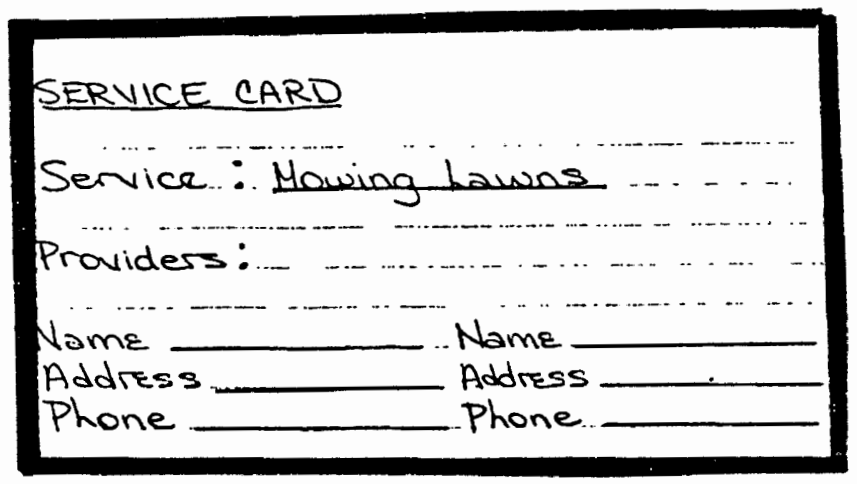

In doing this canvassing, the staff found that often people do not relate to the word "helping." They see themselves as "just friends" and their exchange as mutual, like the grocery owner who sprays roses 
for a woman who bakes him bread every week. The help that these people give, although viewed merely as friendly acts, is often crucial to their elderly neighbor.

Because this lady lived next door to Mrs. A and was willing to check every day and make sure her blinds were up, make sure she was there, and $\mathrm{OK}$, she was eating and that sort of stuff, Mrs. A. didn't go into the nursing home until recently. Then she had a major fall and a stroke, and she couldn't stay.

BUILDING THE RELATIONSHIP

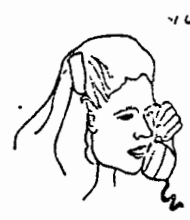

The process of learning about and recording helping patterns is a slow and never ending one.

It took a long time and a lot of conversation before the center staff had a clear idea of helping exchanges. We had to keep going to visit and keep talking.

In time, people begin to trust the center staff enough to tell them about their informal helping. The entire staff also works at being good neighbors and has gained a reputation for "going the extra mile". As people see how hard they work, they begin to trust them more and share more with them. 


\section{GOING THE EXTRA MILE}

We take the time to visit those confined to

their homes or nursing homes.

We maintain contact with people in this area.

We send cards on birthdays, anniversaries, when someone is sick.

We try to remember children's names.

We all go to funerals.

WORKING PROCEDURES

WORKING WITH NATURAL HELPERS

The staff uses the information they obtain about helping networks in a variety of ways:

1) They try to relay information between neighbors they know are acquainted. "Do you know that Mr. W. went into the hospital?"

2) Sometimes they open up new situations. 
One woman's husband died. After two months when the shock hit, her supports were gone. We told a neighbor that she needed to be looked in on. She went over and spent the night! She really helped a lot after that.

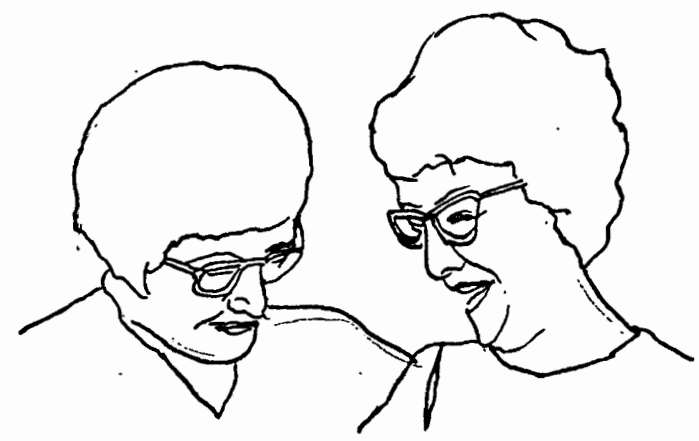

3) Once in a while they call on a known helper to check up on a friend when something seems wrong. It doesn'.t always work out perfectly.

Once Mrs. S. missed an appointment here. She never misses appointments. I called her apartment manager who we had already identified as a helper. He knocked, got no answer, and then unlocked her apartment. He found she had washed her hair, had taken her hearing aid out, and wasn't happy to be interrupted.

They guard the information given to them in trust. They do not share it with other agencies for any reason.

We are sometimes seen as uncooperative by other agencies, but we won't violate the trust of people. They would never trust us again.

\section{EVALUATION}

This center does not formally evaluate its work with natural 
helpers, but would be able to measure how much work it does because it keeps such detailed records on index cards.: Three indicators of the amount of work they do could be:

1) How often they're recording on the cards.

2) How often they use existing information on the cards.

3) How many people receive calendars and a visit from a block worker or staff member each month. 


\section{Settlement House II}

DESCRIPTION

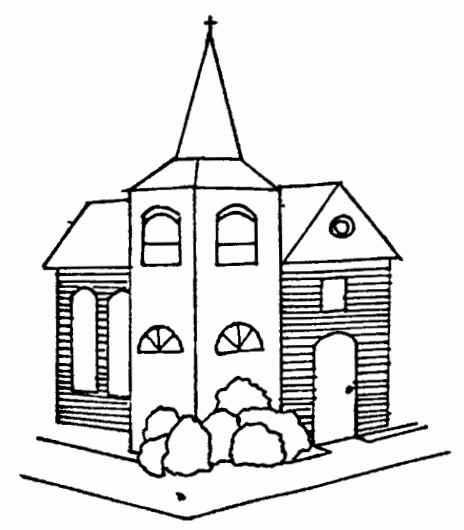

Settlement House II is a multi-service center that works with natural helpers in its programs for the elderly. The program for the elderly is designed to coordinate existing services for low income elderly and to provide outreach and counselling. Their goal is to provide access to services and to address the social isolation of the elderly. They are working with natural helpers becuase they believe natural helpers can do more to alleviate social isolation than agencies can. They also believe that natural helpers provide many of the essential services for the elderly. Primarily, the settlement house attempts to locate natural helpers and to support and encourage them in what they are doing. They exchange information and act as back up for natural helpers when they're unable to provide a service.

We interviewed the director of the elderly program, an outreach worker, and a field worker. The field worker had the most direct contact with natural helpers. Her work is outlined below. 
WORKING WITH NATURAL HELPERS

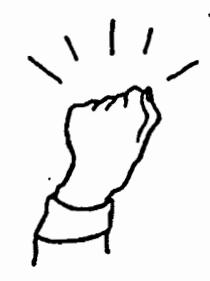

How the Agency Works With Natural Helpers

The field worker we talked with described how she works with natural helpers in four stages:

1) Learning the neighborhood.

2) Locating the natural helper.

3) Developing the relationship.

4) Working together.

Learning the Neighborhood:

Before doing any work with natural helpers the worker gets to know the neighborhood. She follows seven steps:

\section{LEARNING THE NETGHBORHOOD}

1) Learn the streets and natural boundaries.

2) Visit the churches; talk with the church officials to find out their role in the community.

3) Visit the stores and shopkeepers.

4) Visit the community services in the area.

5) Get to know the people with power through attending neighborhood association meetings. 


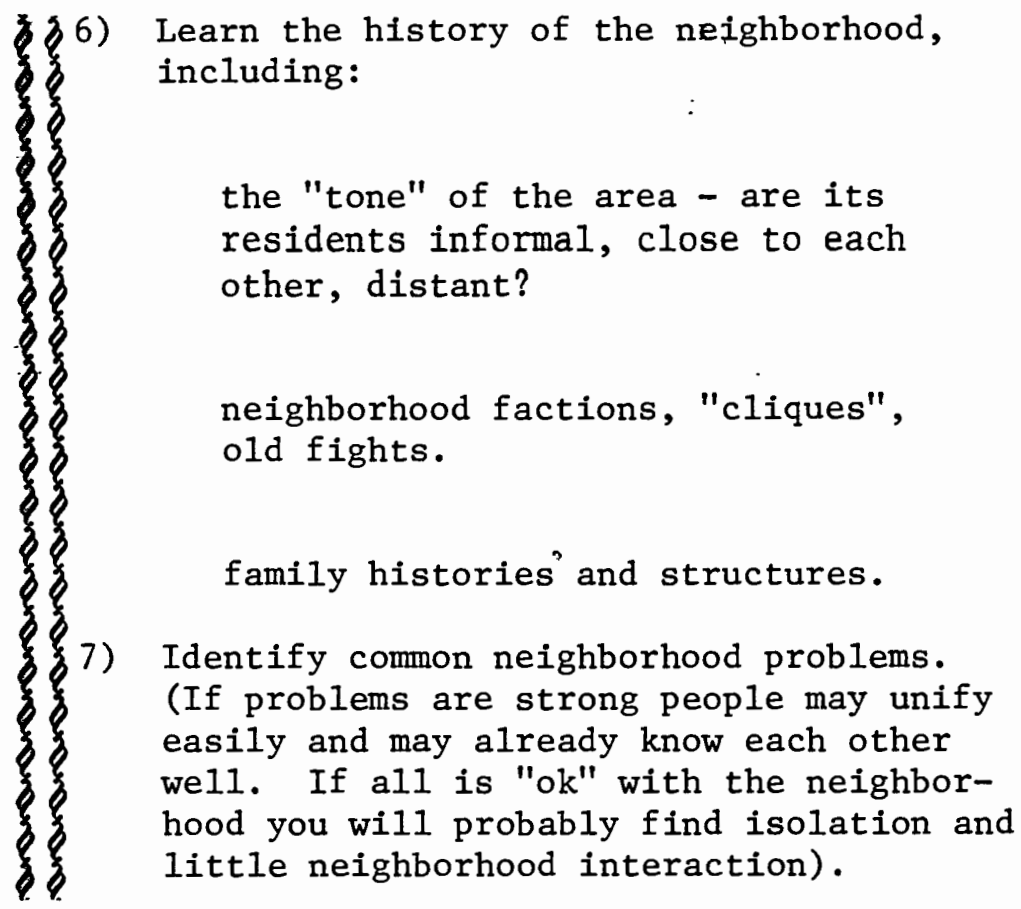

Locating the Natural Helper:

This field worker often finds natural helpers while doing doorto-door outreach. Two or three people on the same street may all refer to one person who is helpful. Sometimes she finds them by accident; for example, Mrs. $\mathrm{X}$ who regularly calls the agency about Mr. Y. turns out to be a natural helper. Others are located as a result of getting to know the neighborhood.

Developing the Relationship:

Once a helper is identified, this worker feels developing the relationship in a relaxed atmosphere is essential. She usually begins over a cup of coffee, chatting about the neighborhood in general and about the helper's family and activities. The time she spends 
initially is often longer with older adults. She brings an agency brochure and talks about the services the agency offers.

If the helper is receptive, she explains how the agency might assist the helper, and, in turn, how the helper might assist the agency. She feels it is important to convey the attitude that what the helper does cannot be replaced by the agency. She keeps in mind the rule, "do not displace the helper", and abides by what she calls "the rules of community organization":

$\xi \xi$ 1) Don't take over.
2) Abide by what they want and/or need to do.

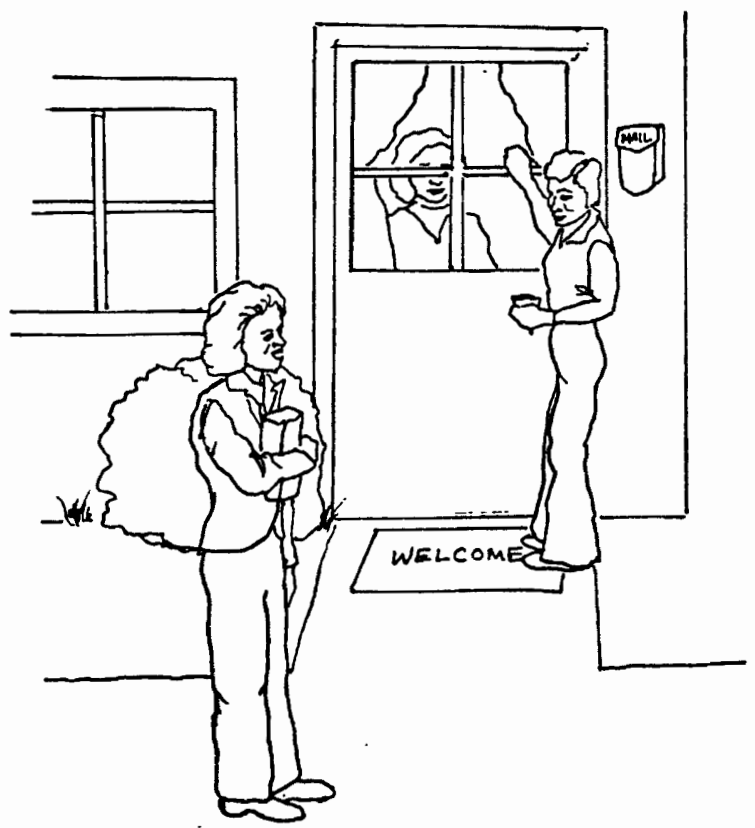


Once a relationship has been established, the field worker deliberately:

1) Calls frequently, just to say hello and to chat.

2) Drops in spontaneously.

3) Attends neighborhood funerals and functions.

It's a casual procedure, but done very deliberately.

working Together:

In addition to supporting the natural helpers' work through visiting, the settlement house shares information with the natural helpers. The worker lets the natural helpers know about new services, and the natural helpers let the agency know about problems they feel need professional attention. The natural helpers are encouraged to call the agency for back up when they are unable to provide a service, for example, transportation.

\section{Problems Encountered:}

The field worker felt there were two main problem areas in working with natural helpers, factionalism in the neighborhood and termination.

Factionalism in the neighborhood makes it hard for workers to remain neutral. They are often identified with one "side" or another, and sometimes may become alienated from members of a community, 
destroying potential for work with natural care givers on the "other side". The worker we talked with feels caught in the middle when this happens.

Termination may include the death of a natural care giver, a natural care giver moving out of the area, or "burn-out". In these cases, the agency may take over, or may ask another natural helper to consider stepping in.

An 85 year old woman was being cared for by a 50 year old neighbor woman. Due to exhaustion the neighbor (care giver) appealed to us. We put the woman needing care on our total home-care service. The 50 year old is grateful and can still help some. The 85 year old is relieved and doesn't feel as much of a burden to her friend. This helped to preserve their relationship.

EVALUATION

The field worker keeps track of all her contacts with natural helpers to give herself an idea of how much work she is doing. She gauges the success of her work by the number of times the natural helpers call her. 


\section{Chapter Six}

\section{Working With Natural}

\section{Helpers: Working with Kids}

Chapter Six contains a description of the only program we interviewed that works with teenage natural helpers. The staff have developed a structured program, in order to co-ordinate with a local high school and a variety of agencies that serve youth.

Many programs see information sharing as an important part of working with natural helpers. This program is an example of one that makes providing information to natural helpers its primary goal. They believe that kids are good helpers. They don't need training, they just need a way to get correct information. 


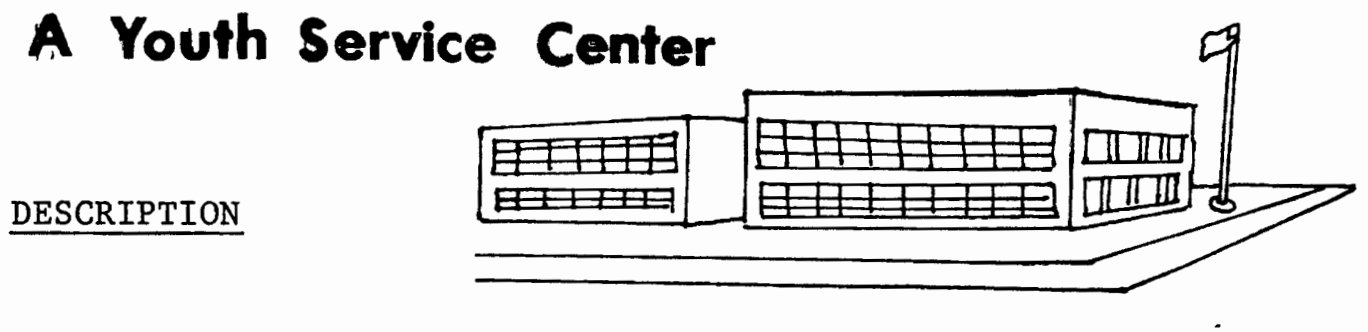

This youth service center serves one quadrant of a large city. In one of its programs it works with young natural helpers. The helper program is neighborhood based, focusing on one high school located a few blocks from the center. We talked with a worker from the center who helped develop the program.

The philosophy of the center and of the program with natural helpers is that kids can and do take care of themselves if they're given a chance. The program tries to give them this chance and help them in their efforts.

We believe kids can do
it...If they're given
a chance, they'11 do
alright... We try to
give them the chance.

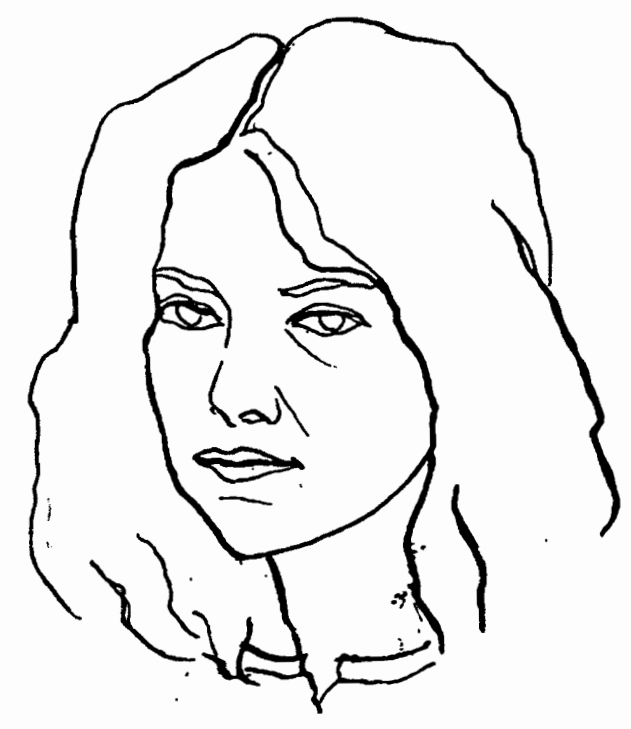


WORKING WITH NATURAL HELPERS

The Teenage Helper Program

This program is specifically designed to assist teenage helpers. The woman we spoke with explained that kids who need help go to their friends first. Friends are in the right spot and already have a trusting relationship with each other.

Kids go to friends first... Friends know about problems from the start... We don't see the kids until two months later, when they're in crisis.

She feels kids are experts in giving support with relationship problems or problems at home but are not experts in giving technical advice such as what to do about VD or a pregnancy. Here they are apt to pass on old myths or fears. The main purpose of the program is to give young helpers better information about resources that can provide such technical information.

They are already helpers...We're just making sure the information they're giving is correct. 
"Recruiting" the Helpers

The program is run in co-operation with a local high school. Originally staff talked to four junior and senior level psychology classes to "recruit" interested students. The students receive psychology credits for attending the weekly meetings and for visiting local agencies serving kids. The program lasts one semester.

The staff assumes that all of the students help their friends in some way. They do not recruit for a special kind of helper.

We do not expect the kids in our program to help everyone. If they just meet the needs of their friends better, that's great.

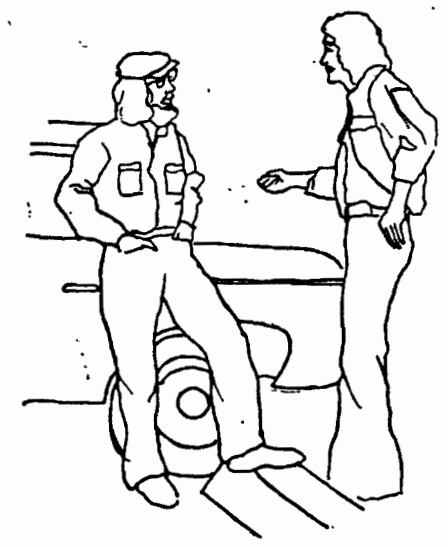

They have found that a wide variety of kids participate for different reasons. However, the most "dedicated" kids often have grown up in the area and know its special problems.

The kids who are the most dedicated are the ones who have grown up here, who know the kinds of problems and the extent of the problems. They really feel they want to do something. 
Building the Relationship

Getting information to the kids is the main aim of the program. Secondary aims are building and maintaining trusting relationships with the kids so that other kids will become interested in the program, thereby increasing the network of helping youth and giving support to the kids for what they are doing. Weekly group meetings are designed to accomplish these aims. The program staff is available to the kids at any time the kids want to get in touch with them as well.

Program staff feel several things are important in establishing a trusting relationship:

1) Avoid "laying" your values or opinions on the students.

2) Avoid jargon. Your professional words may prevent communication.

3) Avoid overloading students with information. Go slowly.

Working with the Young Helpers

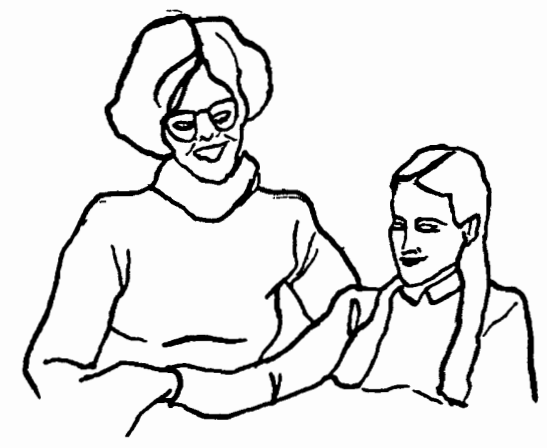

The program works with helpers in four main ways:

1) Increasing their knowledge of resources. 
2) Supporting them in what they do.

3) Increasing the network of helping.

4) Encouraging them to develop their own projects to help others.

Increasing helpers' knowledge of resources is the main focus of the project. Since the program views kids as capable helpers, the work they do with them supports the help they're already giving. They do not teach the helpers how to help but rather give them a chance to increase their knowledge of service resources so that they can share it with their friends and others they help.

Program staff accompany kids on hour long visits to local agencies which provide services to youth. The kids themselves determine the agencies they want to visit through identifying the problems and needs they hear about most often from those who come to them for help.

Supporting the young helpers for what they're already doing is another focus of the program. Weekly group meetings give them a chance to talk about the ways they help each other. They get support and encouragement from each other as well as from program staff. The staff also makes it clear to the kids that they are available by phone or in person any time the kids want to talk with them.

The program also encourages helpers to set up projects of their own through the center. For example, one young woman in the program started a support group for high school students who are parents because she was a parent herself. 


\section{A Problem to Avoid}

One problem the program anticipated ahead of time and decided to tackle before it became a problem was parental concern and consent. They set up a meeting with the parents of interested kids before the program started to explain what the program would do and to answer questions the parents might have. Parents were enthused about the program and even said they wished there was a program like it for themselves.

We never heard any complaints about the program from the school or the parents!

EVALUATION

The program tried to measure whether or not more kids were helped as a result of the program. They asked helpers to keep a personal journal of all their helping contacts. This was to serve as a record of growth in the number of contacts. However, they found that most kids did not record the help they gave friends, so the measure was not accurate.

In most cases the only contacts they record are people they didn't know before. They don't consider the rest "help". 
A Youth Service Center

65

The worker we spoke with mentioned two other measures of success.

The program has recorded increases in referrals from the high school they work with to the agencies visited by the helpers, indicating that better resource information is getting to the kids. Equally significant, the program has received requests from two other high schools to start similar programs.

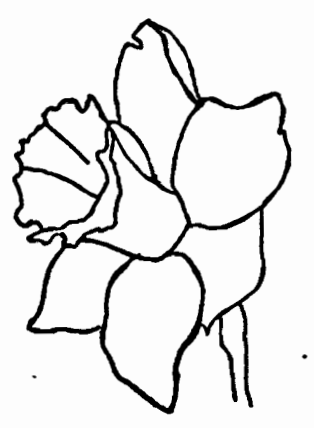




\section{Chapter Seven}

\section{Working With Natural Helpers: Improving the Quality of Life}

The two programs included in Chapter Seven operate from an "enabling" philosophy. They try to improve the quality of life for residents of the areas they serve by helping to empower the residents to take responsibility for meeting their own needs. As a result they encourage natural helping from people who may not have done it before and provide a mechanism for people to get involved in helping in a variety of ways. The staff from both programs go out of their way to involve people from their areas in volunteer, helping activities. Both programs call many kinds of helping :"natural" helping; neither defines natural helpers in the pure sense that we defined them in Chapter Two.

The inner city project focuses on the elderly and the neighborhood health service focuses on all age groups. Each works within its focus to "enable" residents of its area to take responsibility for improving the quality of life within their community.

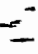




\section{An Inner City Project}

\section{DESCRIPTION}

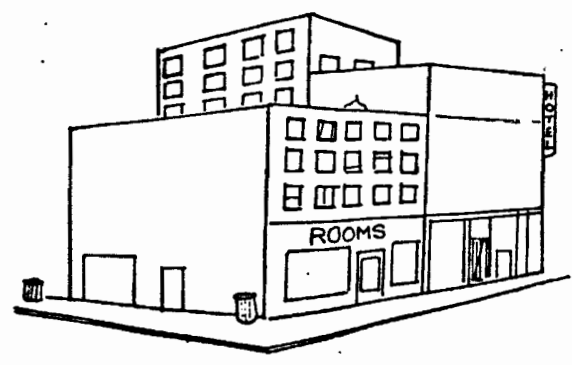

We interviewed the director of an inner city project providing services to the elderly. The project has a small staff and is neighborhood based. It provides housing services, information and referral, visitation and hotel management. The staff is concerned with helping all people (staff, clients, volunteers, other workers, etc.) "to utilize their self potential, to become alive with respect and dignity."

Our job will be done when everyone naturally loves one another and helps each other.

WORKING WITH NATURAL HELPERS
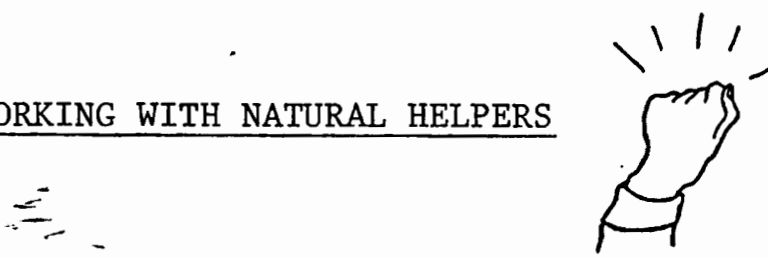
-

The project works both with the neighbors of their clients and with over 200 volunteers. Some of these people would fit our 
definition of natural helpers. Some only help as an extension of their job. Some are agency volunteers. The project does not make a distinction among these helpers. It will work with any person involved with the elderly, in order to improve the quality of life for the elderly. The director described how the project works in two of their service areas: the visitation service and the hotel management service. This last service is one provided to hotel owners.

The Visitation Service

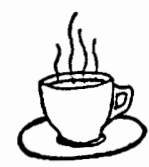

The visitation service (provided mainly by volunteers) is our basic service. It underlies all our other services. We don't even like to call it a service.

We recruit volunteers to work on a one-to-one basis with an aging person who has no natural support system. It is a two-way street. Our volunteers don't go into a person's life and say, "I'm going to help you Mac. Aren't you lucky?"

Our volunteers are trained to initiate the relationship that results in a human relationship. There's trust... argument...honesty...authenticity. The volunteer ceases to become a volunteer and is just another person in someone's life - part of an extended family.

These are long-term, sustaining relationships. Often at the graveside there's only the volunteer and myself.

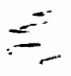




\section{The Management Service}

The project has recently begun to contract with hotel owners to provide project staff as hotel managers.

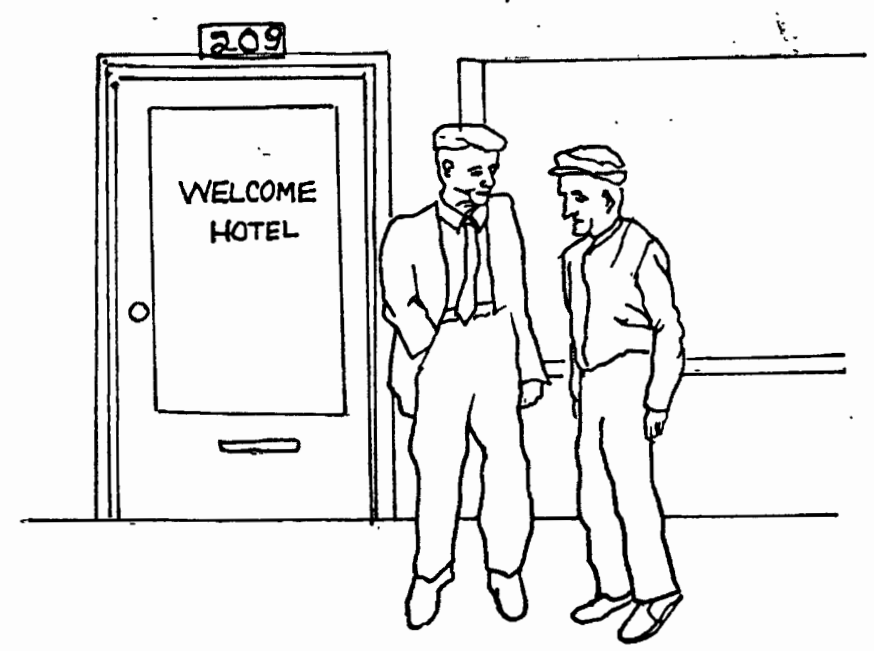

We are trying to build into the hotel a management that is receptive to the tenants and to the neighbors who live in the vicinity and work in the vicinity.

The owner of the hotel will work with us. She is going to introduce our managers to the man who runs the cafe across the street. G.F. is 85 years old, a delightful guy. She's going to introduce them to $G$. the bartender who runs the bar at the Chinese place, and to $\mathrm{L}$. the former college professor who runs a shop nearby...

Our management service will not be a building confined service, but one that works with our neighbors...

There hasn't been enough listening to the people who run the shops to see what they're already doing - have been doing for years...

We try to involve people in the area so that the work is natural, not a "service". 
Building Relationships

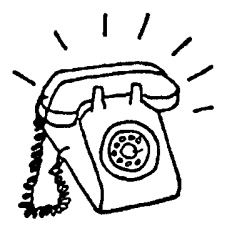

In all their work with helpers, the project staff stress the importance of building relationships. They don't think they can make any significant changes in how a helper works with the elderly until they have established a trusting relationship. Once the staff person and the helper trust each other, they can begin to criticize each other and help each other make changes.

After you're on an equal relationship with trust, you can criticize. They know you like them and will listen.

Some guidelines for building relationships that the director repeated over and over again were:

\section{Guidelines}

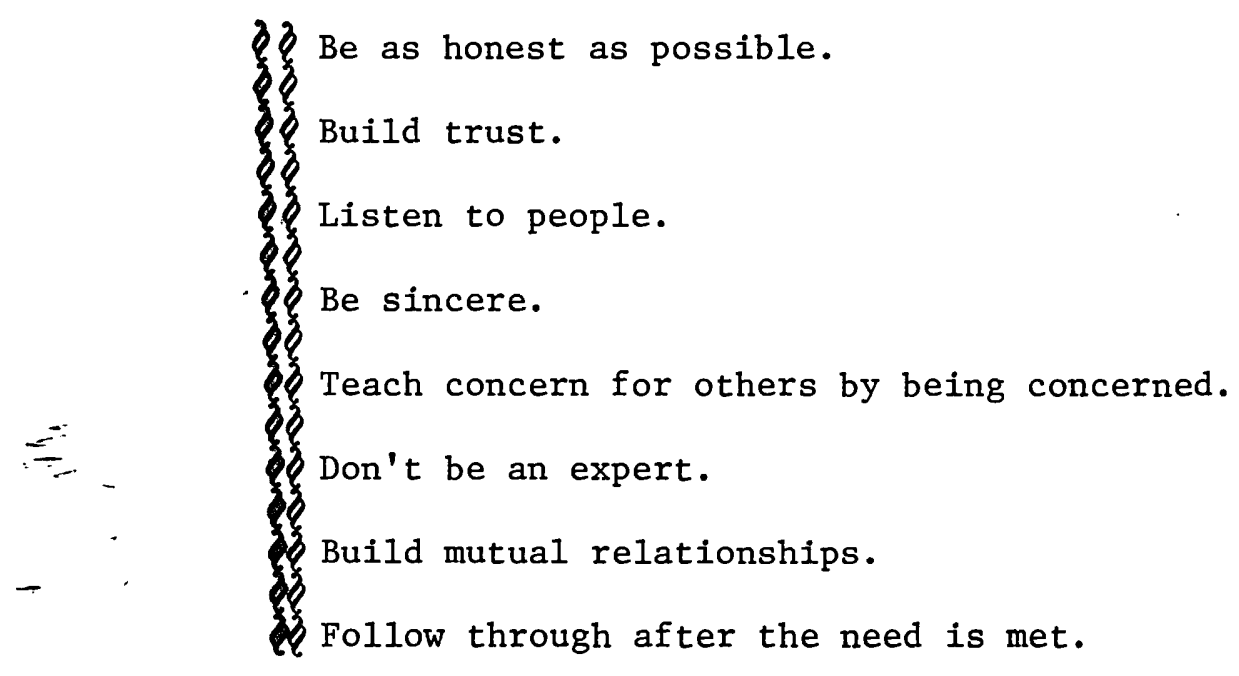




\section{EVALUATION}

The staff director hopes that as he and his staff treat helpers with trust and concern, the helpers will increase their concern for the elderly. He looks for changes in the way helpers relate to the elderly as one measure of the success of the project. He gave an example of working with one hotel owner over a period of many years. Originally, the project asked the owner only to provide space in his hotel for a recreation program. After the program had been running for some time, he volunteered to provide food for the recreation sessions. He also began to show more concern for his residents in many ways. One example is that he began to attend resident's funerals. "That's success!"

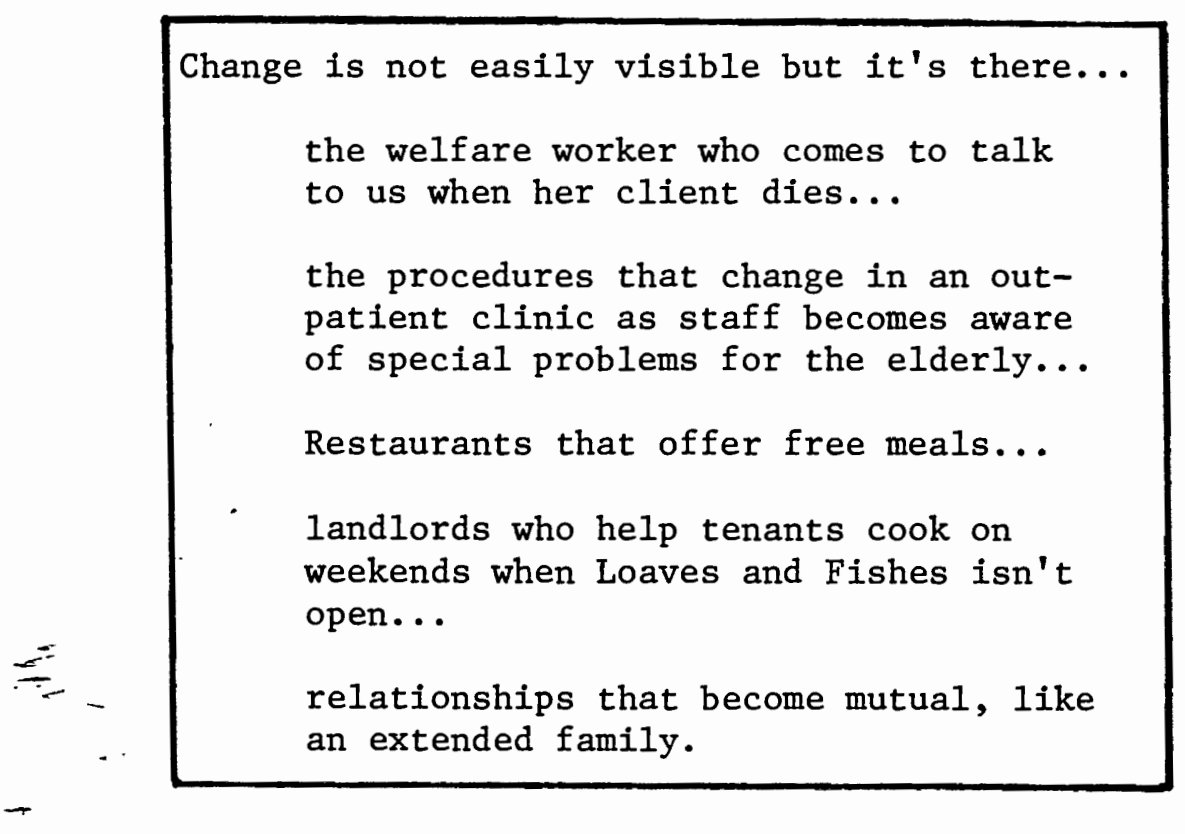




\section{A Neighborhood Health Project}

DESCRIPTION

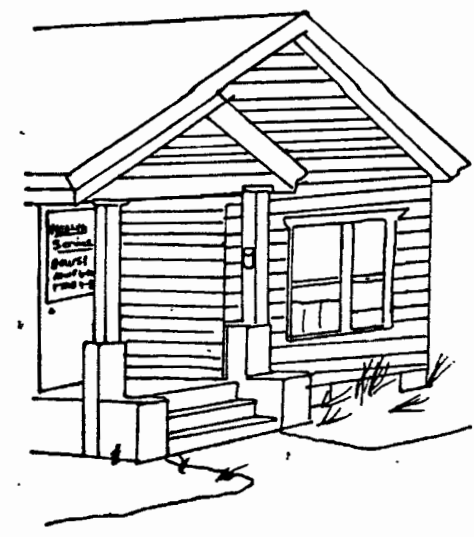

The neighborhood - based health service works with natural helpers because they see it as a way to improve the quality of life in the neighborhood. They also see working with natural helpers as a way to enable neighborhood people to accept responsibility for their own health.

Our guiding philosophy...in enabling people to take responsibility for their own lives is... health care is your right and your responsibility.

They see natural helping as a way neighborhood residents can build their own resources as individuals and as a neighborhood, rather than depending on outside agency help, or even neighborhood agency he

The health service is located in a working class neighborhood of mixed ethnic groups. With the exception of two paid workers, the 
staff is composed of volunteers, many of whom live in the neighborhood. The worker we interviewed, a volunteer nurse,: had lived in the neighborhood for many years, and was one of the people who started the service. She works as the coordinator of the crisis intervention program, recruiting and training crisis volunteers. She is also a resource person, evaluating formal resources and developing informal ones. In both roles she works with natural helpers.

WORKING WITH NATURAL HELPERS

Since the service considers itself part of the neighborhood, it operates in "equal partnership" with neighborhood residents to improve the quality of the neighborhood. Their work with natural helpers reflects this partnership concept; they actively encourage people who are willing to help to reach out to neighbors in need.

Finding the Helpers

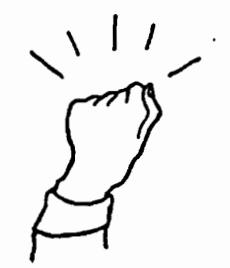

The woman we interviewed looks for natural helpers while she is doing all of her other work. She does neighborhood outreach to individuals, businesses and service centers which involves explaining thé-health service's programs, exploring resources, and looking for natural helpers. Some of her outreach methods are: 
1) She visits public places such as laundries, taverns, and stores; she provides brochures, explains the program's services: to proprietors, and talks to them about their involvement in the neighborhood.

2) She visits neighborhood residents, sharing information about the program and talking to them about the ways they help others.

3) She visits community service centers on a regular basis to keep aware of all the changes in their programs. She gave an example of visiting one neighborhood center where she observed some young men talking to youth whom they felt were "drifting down the wrong path". She recognized these young men as natural helpers and eventually established a partnership with them.

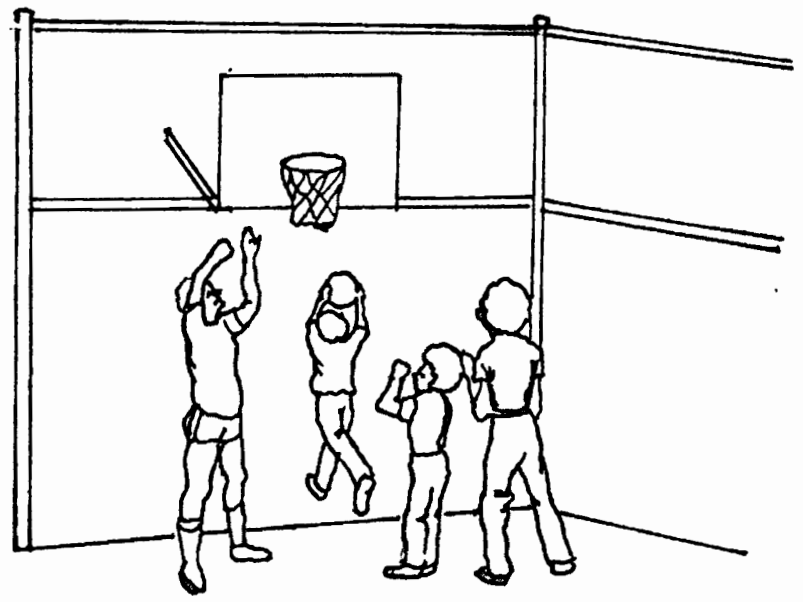

Building the Relationship

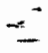

- Although her style is unstructured and spontaneous this worker 
follows a step procedure in beginning a relationship with a natural helper she has identified.

\section{STEPS TO FOLLOW}

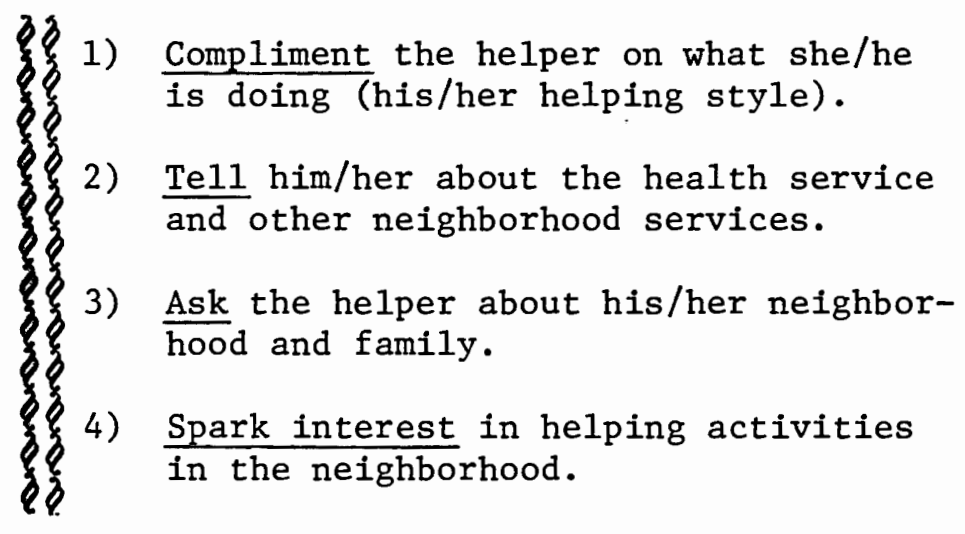

After her initial visit, if she thinks the person has potential for helping, frequent contact is made. This frequent contact is important to building the relationship and giving support. She gives much encouragement, "You can make the right decision", and tries to build self-esteem, "You are doing something no professional can do as well". She encourages much phone calling and does a lot of "dropping in" on the natural helper.

\section{Working Procedures}

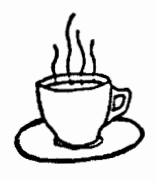

$=$

-The health service makes use of natural helpers as part of their service in five ways: 
1) They keep care givers informed about new and changing services in the neighborhood so that the caregivers can use and share the information.

2) They help set up "new contacts" between helpers and those who need help. Often the help needed is of a tangible nature. For example, they might find a neighbor to bring hot meals to a person or to help with home health care.

3) They try to identify youthful helpers at the community center, provide them encouragement, and act as back up for them in crisis situations that the kids feel they can't handle.

4) Natural helpers who have a special talent for crisis work are used on an "on call" basis. This use of natural helpers grew out of the center's experience with a hot line staffed by trained volunteers who were not necessarily from the neighborhood. They found local residents were not using the hot line, prefering to go to someone they already knew. Referring crisis calls to the local helpers seems to work better.

The agency had a hot line originally, but it was ineffective because this neighborhood does not use strangers for crisis. People go through their pastors and similar neighborhood helpers.

5) Natural care givers are consulted as advisors to the health service, all along the way. Changes are made in the health service as a result of their advice.

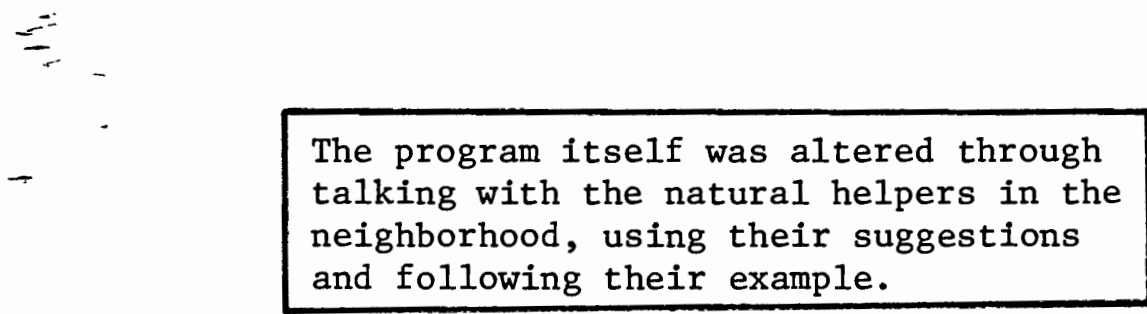


EVALUATION

To evaluate their work the health service staff look for evidence that their goal, strengthening the neighborhood, is being accomplished. If they see people becoming involved with each other and relying on neighbors rather than agencies, the service staff feel the neighborhood is strengthened.

The agency has helped change the neighborhood in several ways: people take pride in their neighborhood; they're talking with each other; they're checking up on old people; some have been volunteers to the agency.

The workers also look for evidence that they are establishing mutual relationships with natural helpers in the neighborhood. Workers feel that one indication that the relationship has become mutual is when helpers call about something they might call a friend or neighbor about.

We know we're making progress when a neighbor calls to find out where to get garbage bags or where to find a babysitter. 


\section{Chapter Eight}

\section{WorkingWith Natural Hel pers: Building Networks}

Chapter Eight contains a description of only one program, which is unique in its focus of working with helping networks rather than individual natural helpers. The staff make no distinction between themselves and the people they work with; they consider themselves part of the helping networks in their area. The director emphasized this strong point, saying, "I'm the client too".

Other programs we talked with both work with natural helpers and provide other services. This program works exclusively with helping networks in the community, building and strengthening networks among childcare providers and parents. The staff is small; there are only three people. They do not try to provide childcare services themselves because they believe that the community can meet its own needs through helping networks. 


\section{A Neighborhood Approach to Child Care}

DESCRIPTION

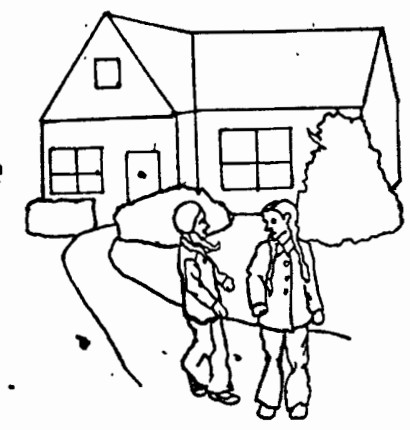

This community program was created to empower one area of a city to meet its own childcare needs without being dependent on state-funded centers. During a funding crisis in daycare a group of concerned citizens organized, chose a stable, working-class neighborhood that needed more childcare, and started to work with residents of that neighborhood to improve the childcare situation. The program now has a staff of three; two live in the neighborhood and one person lives outside of it.

The program now helps to co-ordinate and staff a co-operative daycare center, works with an organization of family daycare providers, publishes a monthly daycare newsletter, acts as a referral center for parents who need daycare, and helps organize parent co-operatives. It tries to develop helping networks between parents and/or providers, feeling this "old way" of caring for children gives control back to the residents of the community.

We interviewed the director of the program. She has been involved from the start and was hired as director when the program 
obtained funding to pay her. She is a resident of the community and has a pre-school child.

WORKING WITH NATURAL HELPING NETWORKS

This program works with helping networks rather than individual natural helpers. The director feels that the potential for helping networks always exists, even if people do not recognize it.

The network is there all the time. You see it when you use it.

Informal helping networks develop when people really need them. For example, in a time of crisis people turn to each other and help each other out. She thinks the current situation with daycare is a crisis and that service workers can assist in solving this crisis by working with people to develop helping networks.

When in a crisis situation, people will network. Childcare is now in a crisis situation.

$=$ Her program began out of the need for improved childcare, with the goal of empowering the community to meet its own needs. It has chosen both developing new helping networks, and strengthening existing ones as a way of meeting this goal. 
Developing Helping Networks

In beginning its work this program sought to involve the people in the community who had vested interest in daycare - the parents and the family daycare providers. When they found interested people, the staff tried to develop helping networks among them so that they would experience controlling their own daycare.

We struggled to get people to believe the control is there -- with them.

They began to develop networks among two groups: among the parents and among the family daycare providers.

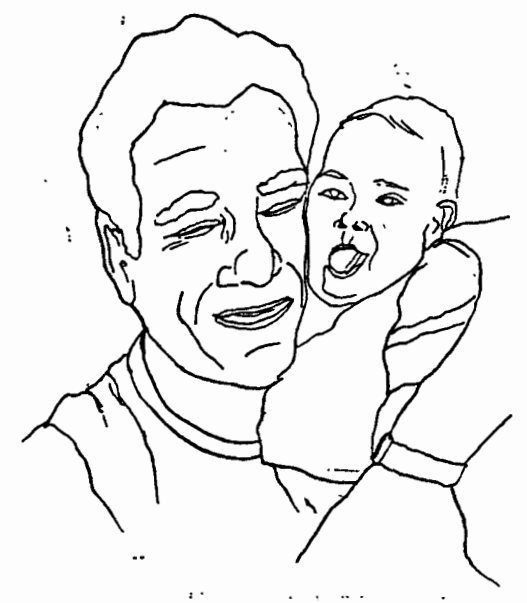

With Parents:

$$
\begin{aligned}
& \text { To get parents involved in their program the staff: } \\
& \text { 1) Talked to community groups, church groups, PTAs, } \\
& \text { neighborhood associations, etc., about daycare }
\end{aligned}
$$


needs in the community and what people could do about them.

2) Contacted any people they heard were interested in daycare, talked to them, and tried to get more names.

We started with a list of five or six people. We talked to them and got five or six more names...

3) Asked interested people to hold coffees in their homes and invite their neighbors. In this way people with similar needs began to meet each other and friendships developed.

In all their activities the staff tried to help people identify childcare issues and find ways that they could meet their needs together.

With Daycare Providers:

To get family daycare providers involved in their program the staff:

1) Obtained a list of licensed providers from Childrens Services Division and went door-to-door, talking to all of them.

2) Returned to talk informally with the providers about their problems, looking for ways that they could be

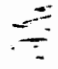
of assistance to these women.

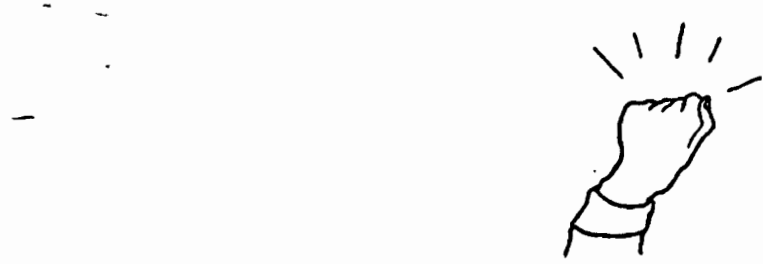


often it took a whole day! We tried to give them support for their work and be an outside contact. They are often isolated in their homes and don't know each other. They were grateful to have someone to talk to.

3) Held a coffee in one provider's home. At this meeting some of the providers organized into a group.

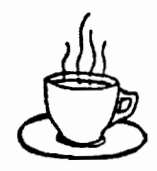

4) Helped the new group of providers write a pamphlet describing their organization and send it to other providers in the community.

Strengthening Helping Networks

Once helping networks started to develop the program tried to strengthen them, both by encouraging the establishment of co-operative systems that new people could link with and by assisting community residents to find local helpers.

With the Parents:

With the parents in the community the staff:

1) Has set up a "little peoples' exchange" where each parent gets 50 tickets. Each ticket may be traded for one hour of babysitting. Therefore, to get more tickets, a parent has to sit for others in the exchange.

2) Provides a referral service for family daycare.

They visit all daycare homes so they can accurately refer parents. 
They try to give parents a variety of choices, knowing different people have different needs.

They request feedback on all their referrals.

3) Wrote a pamphlet about how to choose a daycare home that is available to all parents.

4) Works with parents to help them develop their skills in choosing and working with daycare providers. If a parent is having particular difficulty, they will even visit the provider with him/her and try to help.

5) Provides a list of teenage babysitters. (When they found that these young babysitters needed help in skills and in learning how to avoid being taken advantage of they developed workshops for them in these areas and advertised in the local high schools. They are as interested in empowering teenage babysitters as they are in helping daycare providers or parents.)

With the Providers:

To strengthen the helping network of daycare providers the staff:

1) Works with providers to solve mutual problems, helping them to recognize their own power. An example of this work is their organizing of providers to write letters to a U.S. Senator about a recent tax law that was unfair to family daycare. When the law was changed retroactively the group felt it had an impact and was strengthened.

2) Acts as a resource for providers in many ways.

They run workshops for providers. Originally they offered workshops they thought providers would like and found no one came. Now the providers choose the topics and the workshops are well attended.

They have agreed to be a central sponsor for providers when one was needed in order for the homes to be eligible for USDA funds. 
They have established an equipment exchange for providers, providing funds for the original purchases, space to store the equipment, and a delivery service for providers who can't get to the exchange.

3) Facilitates communication among providers by helping to write and distribute a monthly daycare newsletter to 400 people, including almost 100 providers.

The Staff as a Part of the Networks

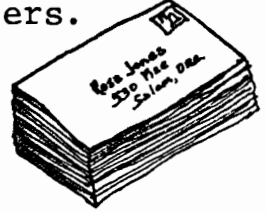

The staff of this program see themselves as a part of the networks they work with. They identify with the neighbors and the community, and are committed to the program on a personal level. "I'm a client too" comes across in everything they do. Their job description includes:

BE EVERYTHING TO EVERYBODY ALL THE TIME

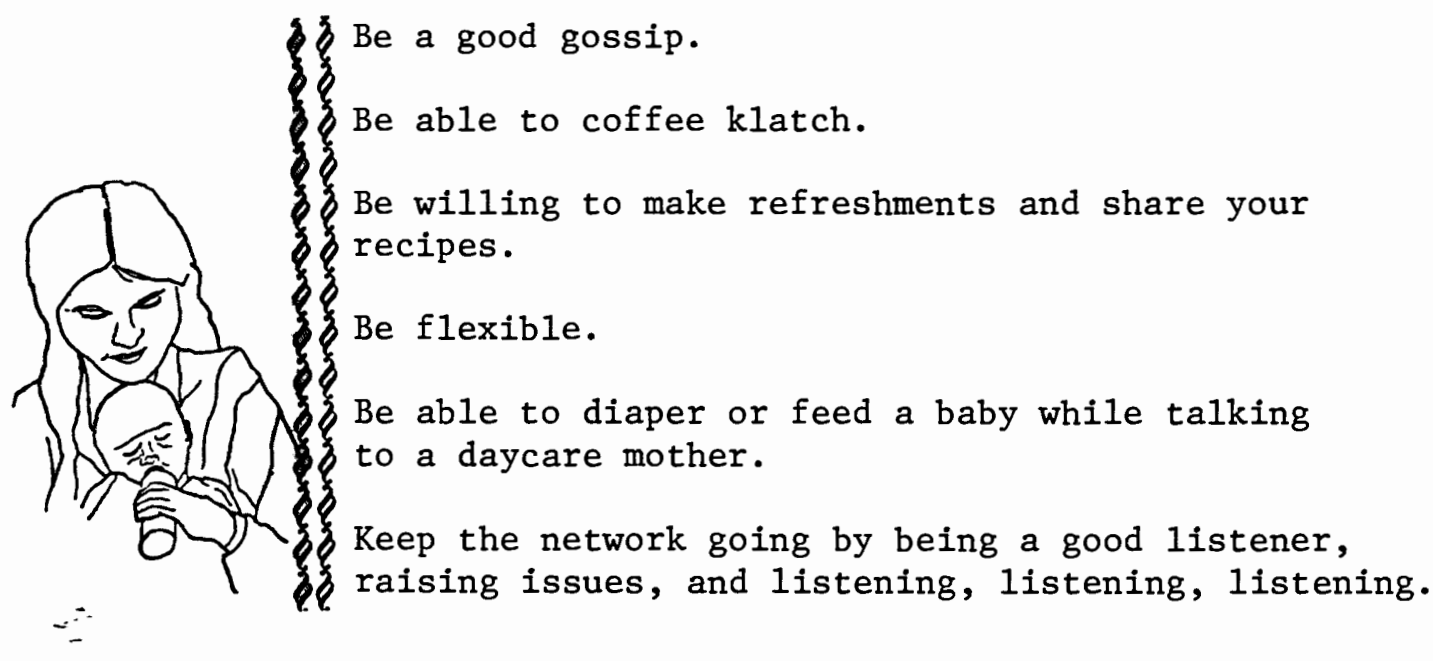

- The staff also uses their professional status and skills to help the networks. For example, the director may lobby legislators 
or write a grant for a needed service.

The director was clear that there are problems with defining your job as being part of a helping network. They fall into two areas: the emotional drain on the worker and the lack of direct reinforcement for the work done. Because this kind of work is informal, like making a new friend, it cannot be left at five o'clock. This can be draining on the worker.

When you develop a close relationship, it's difficult to turn it off. People call you when they need you - at work, at home, whereever.

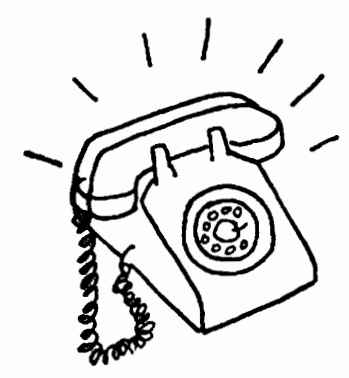

Also, positive reinforcements do not come directly to the worker but come to the parents or to the daycare providers or to whoever has done the work. The director said she has had to learn to find rewards for her efforts in other ways. For example, if she suggests an idea and later people build from it, she feels reinforced for her work.

\section{EVALUATION}

The director uses informal ways to evaluate the program. Because its.aim is to empower the community to meet its own childcare needs, the director feels the program is a success when the people in the community consider the program their own and talk about it in this way. 
She evaluates her own work in building and strengthening helping networks by how people in the community see her. When people talk with her about all sorts of problems she feels she's been successful; she has become part of their helping network.

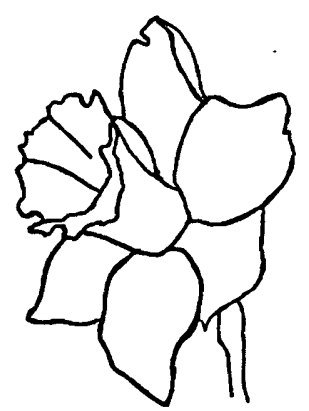




\section{Summary

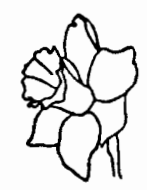

To summarize, we have listed below what we think are key points from the interviews, ones to keep in mind while working with natural helpers:

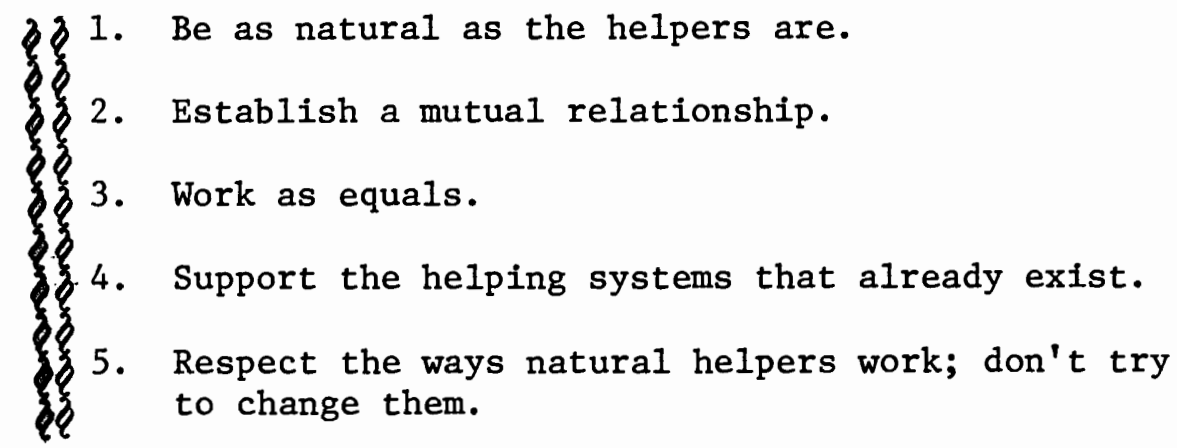

If you can keep these points in mind you should be able to work with natural helping systems without interfering or doing irreversible damage. Like the workers we talked with who developed their own ways of evaluating their work with natural helpers, we encourage you to develop ways to check whether or not you are keeping the key points in mind.

We hope you stay on "the right track"! 


\section{Suggested Readings}

DESCRIPTIONS OF NATURAL HELPERS

Patterson, Shirley, "Indigeneous Helper Value Orientations: An Examination of Differences and Similarities between Age Groups", Journal of Social Welfare, (April, 1974).

This article reports study results that showed differences in helping styles among age groups, and related these styles to helpers'values. The author concluded that the differences were probably due to environmental influences as well as age differences.

Patterson, Shirley, "Toward a Conceptualization of Natural Helping", Arete, (Spring, 1977).

This article summarizes a 1969 grant project completed by Ms. Patterson in Lawrence, Kansas, which explored the use of natural helpers in mental health. The article contains a description of some of the differences between natural helpers and paid helpers, focusing on values, on kinds of help given, and on problems encountered. Advantages of making use of natural helpers are described, as well as the author's view of what professionals can give to and get from natural helpers. 
Patterson, Shirley and Twente, Esther, "Older Natural Helpers: Their Characteristics and Patterns of Helping", Public Welfare, (Fall, 1971).

This article described influences older natural helpers feel have had an effect on what they do in helping others and describes how they view themselves as helpers in their communities.

WORKING WITH NATURAL HELPERS

Collins, Alice H., "Natural Delivery Systems: Accessible Sources of Power for Mental Health", American Journal of OrthoPsychiatry, Vol. 43, No. 1 (January, 1973).

This article describes a method for professionals in mental health settings to work with natural helpers in a consultation model. The article discusses the author's view of natural helpers as "experts" in what they do, and her view that training of natural helpers is therefore not desirable. She proposes rather, the suggestion that since natural helpers are experts in what they do, they want to improve their service. and will benefit from consultation with professionals.

Collins, Alice H. and Pancoast, Diane, Natural Helping Networks: A Strategy for Prevention, NASW Publications, Washington, D.C., 1976 .

This book describes a social network approach to helping, utilizing a concept that describes "central figures" in a network as possible people for professional social service workers to work with as "Iinks" to these networks. A consultation method for linking professionals with central figures is described.

Collins, Alice H. and Watson, Eunice, The Day Care Neighbor Service: A Handbook for the Organization and Operation of a New Approach to Family Day Care. Field Study Report, Portland State Univer$\therefore \quad$ sity, Grant No. R - 287 (HEW), Portland, Oregon, 1969.

This book describes the results of a demonstration project that organized a day care service in an urban neighborhood, linking central figures in the neighborhood through a consultation method with professional social workers. 
Patterson, Shirley, "Utilization of Human Resources for Mental Health, Final Report", Grant No. MH 16618, NIMH, University of Kansas School of Social Welfare, Lawrence, Kansas, June, 1969 to December, 1972.

This report describes types of problems encountered by natural helpers in a rural Kansas area, how paid workers worked most effectively with natural helpers, and the nature of the natural helper paid helper relationship. A method of defining ways natural helpers differ in technique from paid helpers is described. The concept of "mutuality" in relationships between natural helpers and those they help is described.

Smith, Sarah, Natural Systems and the Elderly: An Unrecognized Resource, Project Report, Oregon State Program on Aging and School of Social Work, Portland State University, Portland, Oregon, 1975.

This book described the results of a project that organized a team approach for an urban neighborhood agency to consult with natural helpers among the elderly in its neighborhood service area. Finding the natural helpers, gaining entry with them, and "linking activities" are described.

Watson, Eunice, "Trailer Court: A Day Care Neighbor Approach to Protective Services", field study of the Neighborhood Family Day Care System, Portland, Oregon, 1972.

This report described results of a demonstration project that worked with managers of trailer courts who acted as "link" people between neighborhood families and Protective Services.

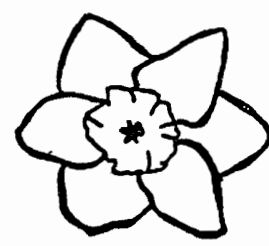




\section{A LIST OF WORKS CONSULTED}

\section{NATURAL HELPERS}

\section{A. Descriptions}

1. Davenport, Marge, "Neighborhood Pharmacist, Ending Career, Closing Store", The Oregon Journal, November 15, 1972.

2. Holtzhuter, John and Patterson, :Shirley, "Age Differences in Help-Giving Strategies of Natural Helpers", presented at the 25th Annual. Gerontological Society Meeting, San Juan, Puerto Rico, 1972.

3. Norris, Glendale, "Some Natural Helpers in Inman and Florence, Kansas", Prairie View Mental Health Center, Newton, Kansas, 1972.

4. Patterson, Shirley, "Indigeneous Helper Value Orientations: An Examination of Differences and Similarities Between Age Groups", Journal of Social Welfare (April, 1974).

5. Patterson, Shirley, "Natural Helping in Urban and Rural Settings", an unpublished paper, 1974.

6. Patterson, Shirley, "Utilization of Human Resources for Mental Health, Final Report", Grant Number MH 16618, NIMH, University of Kansas School of Social Welfare, Lawrence, Kansas, June 1, 1969 to December 31, 1972.

7. Patterson, Shirley, "Supplement to the Final Report: Utilization of Human Resources for Mental Health", Grant Number MH 16618, NIMH, University of Kansas School of Social Welfare, Lawrence, Kansas, June 1, 1969 to December 31, 1972.

8. Patterson, Shirley, "Toward a Conceptualization of Natural Helping", Arete (Spring, 1977).

9. Patterson, Shirley and Twente, Esther, "Ölder Naturai Helpers: Their Characteristics and Patterns of Helping", Public Welfare (Fa11, 1971).

B. Training Natural Helpers

10.

"Mental Health Helpers: A North Dakota Mental Health Association Project", North Dakota Mental Health Association, 1976.

11. Marshall, Carlton D., et al., "The Indigenous Nurse as a Crisis Counselor", presented at the American Association of Suicidology, 3rd Annual Conference, San Francisco, California, March, 1970. 
12. Potsubay, Richard, "\$100 a Year Therapists--Vermont Nurses", unpublished paper, 1969.

13. Priestly, Philip, "New Careers; Power Sharing in Social Work", in Jones, Howard (ed.), Towards A New Social Work, (Boston: Ruthledge and Kegan, Pau1, 1975).

14. Robinson, Donald, "Gatékeepers", Family Health, Vo1. IV, No. 4 (Apri1, 1972).

C. Working with Natural Helpers

15. Bush, Sherida, "A Family Help Program That Really Works", Psychology Today (May, 1977).

16. Collins, Alice H., "Family Counselling Service: Homemaker", in The Human Services: An Introduction (Indianapolis: Odyssey Press, 1973).

17. Collins, Alice H., "Natural Delivery Systems: Accessible Sources of Power for Mental Health", American Journal of Orthopsychiatry, Vo1. 43, No. 1 (January, 1973).

18. Collins, Alice H. and Pancoast, Diane, Natural Helping Networks: A Strategy for Prevention, (Washington, D.C.: NASW Publication, 1976.)

19. Collins, Alice H. and Pancoast, Diane, "Applying Social Work Skills to Natural Networks: New Wine in 01d Bottles", presented at Annual NASW Conference, San Diego, California, 1977.

20. Collins, Alice H. and Watson, Eunice, The Day Care Neighbor Service: A Handbook for the Organization and Operation of a New Approach to Family Day Care, field study report, Portland State University, Grant No. R-287 (HEW) Portland, Oregon, 1969.

21. Ferleger, Beatrice, "Natural Helping Networks for the Elderly-Improving Service Delivery Through the Informal System", Research Utilization Briets, Community Council of Greater New York, Vol. I, No. 5 (April, 1977).

22. Gallegos, Joseph and Harris, Oleta, "Natural Hetworks: Proposed Draft", Western Research Associates, March, 1977.

23. Halbertsma, J., "Organized Neighborly Help--A Pilot Study of New Forms of Voluntary Aid", Report by the Netherlands Institute for Social Research, 1969.

24. Pancoast, Diane, Case Materials for Natural Helping Networks, unpublished papers, 1978.

25.

"Settlement Approach to Neighborhoods" in Millman, Arthur, Making Democracy Work (New York: National Federation of Settlements and Neighborhood Centers, 1967.) 
26. Schultz, Caro1, Annotated Bibliography on Rural Social Work, 1974.

27. Smith, Sarah, Natural Systems and the Elderly: An Unrecognized Resource, project report, Oregon State Program on Aging and School of Social Work, Portland State University, Portland, Oregon, 1975.

28 . Educational Assumptions for Rural Social Work, Southern Regional Education Board, Manpower Education and Training Project, Rural Task Force, 1972.

29. Wagenfeld, Morton and Robin, Stanley, "The Social Worker in the Rural Community Mental Health Center" in Social Work in Rural Communities, Leon H. Ginsbang (ed.) (New York, N.Y.: Council on Social Work Ed., Inc., 1976).

30. Watson, Eunice, "Trailer Court: A Day Care Neighbor Approach to Protective Services", field study of the Neighborhood Family Day Care System, Portland, Oregon, 1972.

II. CONSULTATION THEORY AND PRACTICE

31. Caplan, Gerald, "Support Systems", Support Systems and Community Mental Health (New York: Human Sciences Press, 1974).

32. Collins, Alice H., "Forming a Partnership: First Steps for Client and Consultant", speech at Workshop in Berkeley, California, 1972 .

33. Collins, Alice H., Pancoast, Diane, and Dunn, June, Consultation Casebook (Portland, Oregon: Portland State University, 1977).

III. NEIGHBORHOOD STUDIES

34. Bailey, Jean, Local Citizens' Participation in Coalition Development (Denver: Foundation for Urban and Neighborhood Development, 1975).

35. Dynamic Social Impact Process for Responsive Energy Development (Denver: Foundation for Urban and Neighborhood Development, 1974).

36. Keller, Suzanne, The Urban Neighborhood: A Sociological Perspective (New York: Random House, 1968).

37. Warren, Rochelle and Warren, Donald, The Neighborhood Organizers Handbook (Notre Dame, Ind.: University of Notre Dame Press, 1977). 
IV. NETWORK THEORIES

38. Barnes, J.A., "Social Networks", Addison Wesley Module in Anthropology (Reading, Mass.: Addison Wesley Publication Company, Inc.).

39. Erickson, G.D., "The Concept of Personal Networks in Clinical Practice", Family Process (1975).

40. Froland, Charles, "Analyzing Social Networks: Implications for the Health Professions", unpublished paper, University of California, Berkely, California, 1976.

41. Garrison, J., "Network Methods for Clinical Problems", in Clinical Methods for Larger Social Systems, Symposium presented at the 33rd Annual Conference of the American Group Psychotherapy Association, Boston, 1976.

42. Gati, F. and Colemen, C., "Community Network Therapy", Amercian Journal of Orthopsychiatry, Vol. 46, No. 4 (1976).

43. Scheurel1, Robert P. and Scherida, Kathleen R., "Social Network Analysis: A Salient Approach for Social Work", Wisconsin Sociologist, Vol. 9, No's. 2 and 3 (1972).

44. Tolsdorf, Christopher C., "Social Networks, Support and Coping: An Exploratory Study", Family Process, Vol. 15, No. 4 (December, 1976).

45. Wagner, Donna L. and O'Brien, John, "Primary Associations, Social Networks, and Services for the Elderly", presented at the Annual Meeting of the Gerontological Society, New York, New York, 1976.

46. Wagner, Donna L. and Keast, Frederick D., "Primary Associations and Intervention Effectiveness", presented at the Annual Meeting of Gerontological Society, San Francisco, California, 1977.

\section{RELATED THEORETICAL WORKS}

47. Dedmon, Rache1, "Mutuality Conceptualized for Direct Service", Clinical Social Work Journal, Vol. 1, No. 3 (Fall, 1973).

48. Hardcastle, David, "The Indiginous Non-professional in the Social Service Bureaucracy: A Critical Examination", Social Work, Vol. 16, No. 2 (April, 1971).

49. Howe1l, M., Helping Ourselves (New York: Pergamon Press, 1968). 
50. Levy, Leo, "The Role of a Natural Mental Health Service Delivery System in Dealing with Basic Human Problems", in Specter, Gerald and Claiborn, William (eds.) Crisis Intervention, Volume II, (New York: Behavioral Publications, 1973).

51. Moos, R., Evaluating Treatment Environments (Palo Alto, California: Consulting Psychologist Press, 1975).

52. Shirley, Ruth, "Formal and Natural Mental Health Care: Client Outcomes", research proposal, Salem, Oregon, 1975.

53. Weiss, Robert Frank et a1., "Altruism Is Rewarding", Science Vo1. 171 (March, 1971).

54. Weiss, Robert S., "The Fund of Sociability", Trans-action, (July/August, 1969).

VI. MANUALS

55. Buhl, Cindy, Jones, Lorrie, and Stoltz, Linda, Contact Person Trainer's Handbook, South East Youth Services Center, Portland, Oregon, 1978.

56. Danish, Steven and Hauer, Allen, Helping Skills: A Basic Training Program, (New York: Human Services Press, 1977).

57. Egan, Gerald, The Skilled Helper: A Model for Systematic Helping and Interpersonal Relationships (Montery, California: Brooks-Cole Publishing Co., 1975). 
APPENDIX A

Workers Contacted

1. Mary Anderson

2. Grace Boys

3. Carol Bryant

4. Maria Cramer

5. Peggy Eckton

6. Carolyn Fogerty

7. Charles Froland

8. Pat Hofmann

9. Sharon Kennedy

10. Lori Jones

11. Mitche11 Lang

12. Kathy Latta

13. Nancy McConne11

14. Cherie McGillivery

15. Cathy Nemmert

16. Diane Pancoast

17. Peter Paulson

18. Robert Phillips

19. Dale Poteet

20. Jo Robinson

21. Mike Robinson

22. Jean Searles
Health Help, Portland'

Marion County Mental Health, Salem

Neighborhood Options in Childcare, Portland

Gresham Senior Citizen Center, Gresham

Multnomah County Intergovernmental

Relations, Portland

Kaufman Center, Eugene

Mental Health Division, Salem

Portland Public Schools

Center for Community Mental Health, Portland

Southeast Youth Services, Portland

Neighborhood House, Portland

Neighborhood House, Portland

Multnomah County Public Health, Portland

PACT, Portland

Tri-County Community Council, Portland

PSU School of Social Work

Northwest Pilot Project, Portland

Adult and Family Services, Portland

PSU School of Social Work

formerly with PACT, Portland

Elahan Clinic, Vancouver, Washington

formerly with Southeast Youth Services, Portland 
Workers Contacted (cont'd)

23. Kethy Seimans

24. Mary Sibers

25. Sarah Smith

26. Sylvia Sycamore

27. Robin Trew

28. Helen Williams

29. Ada Wilson

30. Nancy Wood
Women's Mental Health Project, Portland

Holliday Park Hospitail, Portland

Portland Public Schools

Friendly House, Portland

APPLE, Portland

Neighborhood House, Portland

Providence Hospital, Portland

Friendly House, Portland 
APPENDIX B

Workers Interviewed

\begin{tabular}{|c|c|c|}
\hline $12 / 20 / 77$ & Peter Paulson & Northwest Pilot Project \\
\hline $12 / 21 / 77$ & Sarah Smith & Portland Public Schools \\
\hline $12 / 22 / 77$ & Sylvia Sycamore & Friendly House \\
\hline $1 / 6 / 78$ & Mary Anderson & Health Help \\
\hline $1 / 13 / 78$ & Helen Williams & Neighborhood House \\
\hline $1 / 20 / 78$ & Peggy Eckton & $\begin{array}{l}\text { Multnomah County Intergovernmental } \\
\text { Relations }\end{array}$ \\
\hline $1 / 30 / 78$ & Mitchell Lang & Neighborhood House \\
\hline $2 / 1 / 78$ & Dale Poteet & PSU School of Social Work \\
\hline $2 / 3 / 78$ & Carolyn Fogerty & Kaufman Center \\
\hline $2 / 6 / 78$ & Kathy Latta & Neighborhood House \\
\hline $2 / 8 / 78$ & Cathy Nemmert & Tri-County Community Council \\
\hline $2 / 15 / 78$ & Carol Bryant & Neighborhood Options in Childcare \\
\hline $2 / 17 / 78$ & Nancy Wood & Friendly House \\
\hline $2 / 24 / 78$ & Cathy Seimans & Women's Mental Health Project \\
\hline $3 / 1 / 78$ & Lori Jones & Southeast Youth Services \\
\hline $3 / 3 / 78$ & Robin Trew & APPLE \\
\hline
\end{tabular}




\section{APPENDIX C}

\section{INTERVIEW FORMAT}

I. Telephone Introduction:

We are graduate students in social work. For our practicum we are preparing a manual to help social service workers work with natural caregivers. We are looking for workers who are presently working with natural helpers and would like to interview them about the process. We hope to produce a manual that will provide practical "how to" assistance to workers wanting to establish partnerships with natural caregivers.

For our purposes we are considering natural caregivers to be untrained, unorganized, voluntary providers of help to friends, neighbors, family or others who contact them. They may or may not recognize their heIp giving function as something special, but they are recognized and used by others. For this study we are not concerned with self-help organizations or organized volunteers.

Do you think you have ever encountered natural caregivers in your work?

Have you worked together with them in any way?

Would you be willing to give us an interview about this process?

Do you know anyone else who is working with natural caregivers? 
II. Face to Face Interview Schedule:

We would like to begin with a brief description of your agency.

1) What services are being provided?

2) What population is served? income level neighborhood minorities ages

3) How many clients are served annually?

4) How is the agency funded? source restrictions/requirements fees

5) How is the agency organized? decision-making structure caseload organization supervision

6) From your perspective, what is the agency's central purpose or goal?

7) How long have you worked for this agency?

8) What did you do before?

9) How long have you worked in the field?

10) How did you happen to get into the field?

11) What do you see as your personal goals for your work?

12) Who do you work with directly?

13) How wauld you describe your style of work?

14) Do you feel your goals or style are compatible with the agency's goals and/or orientation?

15) Have you changed your work attitutes or style since working for this \#gency? In what ways?

16) Could you describe your specific tasks?

17) How do you go about them? 
18) What resources do you utilize?

19) Do you ever use informal resources...natural caregivers?

20) Could you describe the situations in which you have used natural caregivers?

We are very interested in the initial stages of this relationship and would like to ask some specific questions about them.

21) How did you discover this caregiver?

22) How (why) did you decide to work together?

23) Were there any special problems getting started?

24) What did you do to overcome them?

25) How often do you see this person?

26) Did you ever see her/him more often? less often?

27) Could you describe your relationship?

28) Has the relationship changed? how?

29) How long have you worked with her/him?

30) What do you offer the natural caregiver?

31) What does the natural caregiver offer your clients?

32) What does she/he offer you?

We'd like to get a description of the caregiver.

33) Age?

34) Description of her/his personality.

35) Family situation?

36) Is there a limit to what this caregiver has to offer in terms of time? energy? 
37) How long has she/he lived in the neighborhood?

38) Are there particular problems that this caregiver can handle?

39) Are there particular skills this natural caregiver has?

40) Are there particular affiliations that help her/ him in her/his work? (neighborhood, work, churches, etc.)

41) Do many people recognize and use her/his skills? (If yes, go on to explain central figure concept and try to fit the caregiver into this mode1.)

Focusing on your work again,

42) How does this work fit with your job description?

43) Is this work considered formal or informal?

44) Does your supervisor know of, approve of, understand, your work?

45) Do other workers know of, approve of, understand, your work?

46) Are others doing this sort of work in your agency?

47) Does this work lend itself to: serving the client better? how? serving more clients? describe. adding a new dimension to clientele? describe. (probe for aged, ethnic groups, those not using the formal system, etc.)

48) Did it open new options? New job descriptions in the agency? Jobs in the community?

49) Did it formalize or stabilize anything?

50) Do you think there is something different in you as a worker that led you to work with natural caregivers? Special qualities you have?

51) Do you have any special tips or advice for other 'workers who might want to try this work? Anything special that worked well for you? That bombed? 